\title{
Supply Chain Transparency
} A case study of SKF Group Purchasing

Master's thesis in Quality and Operations Management

Sri Vidya Srinivas Ganta Sudipta Saha 
REPORT NO: E2018:124

\section{SUPPLY CHAIN TRANSPARENCY \\ A Case Study of SKF Group Purchasing}

Sri Vidya Srinivas Ganta

Sudipta Saha

Department of Technology Management and Economics

Division of Science Technology and Society

CHALMERS UNIVERSITY OF TECHNOLOGY

Göteborg, Sweden 2018 
Supply Chain Transparency

A Case Study of SKF Group Purchasing

Sri Vidya Srinivas Ganta

Sudipta Saha

Technical Report no. E2018:124

Department of Technology Management and Economics

Chalmers University of Technology

SE-412 96 Göteborg

Sweden

Telephone +46(0)31-772 1000

Cover

Sri Vidya Srinivas

Sudipta Saha

Göteborg, Sweden 2018

Supply Chain Transparency

A case study of SKF Group Purchasing

Sri Vidya Srinivas Ganta, Sudipta Saha

Department of Technology Management and Economics

Chalmers University of Technology 


\section{Summary}

This thesis report researches into aspect of transparency in a supply chain of global manufacturing organization. In our case Swedish multi-national SKF AB has been used as a case study with focus on their group purchasing organization. The thesis research explores on defining the acceptable definition of the term transparency in context of SKF along with the attributes, which define transparency in a supply chain (upstream: purchaser supplier) and the factors which drive transparency in a purchasing organization. The thesis also researches into understanding the changes in technology primarily related to supply chain and understand the importance of adoption for effective drive towards transparency.

Owing limited research on the subject topic primarily in the upstream of an organization supply chain, an abductive research structure was adopted. The continuous iteration of literature and findings were used to compile a holistic conclusion to the researched questions. The data for the research has been obtained through qualitative interviews conducted with various stakeholders of SKF Group purchasing department. The theory on transparency, technology adoption model and change management has been used when analysis the data. Action research was carried out to gain detailed understanding of few aspects of the subject topic.

The output of this thesis research, is a general definition of transparency in a supply chain with purchasing as core subject view. The research also provides insights into 6 aspects of transparency and four major drivers namely visibility, communication, competence and technology. The thesis also evaluated on the role of future technologies and how purchasing organization could be made ready to adopt the technologies which drive towards improving transparency. The research throws light on few aspects in an organization functioning which could impend the transparency with in that function.

Finally, the thesis concludes with general conclusion with majority of them focusing primarily towards SKF, but the conclusion could be take away for future research into enhancing transparency. The research paper concludes with specific areas which need to be further researched in understanding transparency in supply chain a deeper level.

Key Words: Transparency, Purchasing, Technology, Adoption, Drivers of Transparency 


\section{Acknowledgements}

Primarily, we would like to thank SKF Group for letting us conduct our master's thesis at the company. We are grateful for having Mattias Gremlin and Johan Ramström for arranging the work and to support with the administration part for conducting a master's thesis at SKF Group Purchasing. The two supervisors, Mattias Gremlin at SKF and Erik Bohlin at Chalmers University of Technology, have been of great support during the entire work as guidance and counselor. We would like to thank all 32 interviewees for letting us interview them and sharing their opinions. Finally, we would like to thank all 2 external organizations for providing valuable inputs to the thesis research. 


\section{Table of Contents}

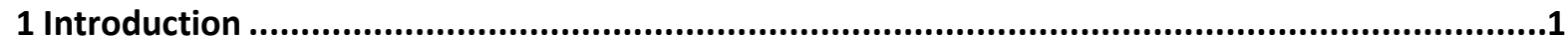

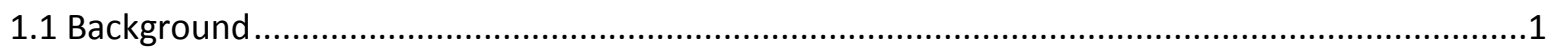

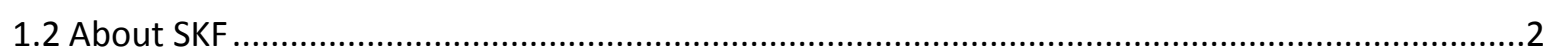

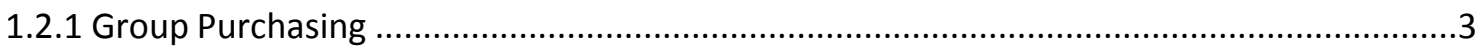

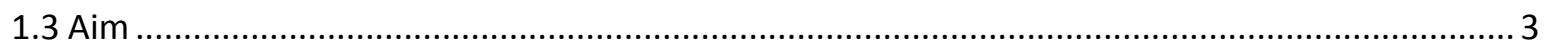

1.4 Scope

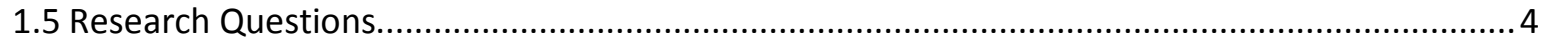

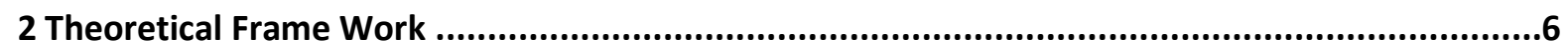

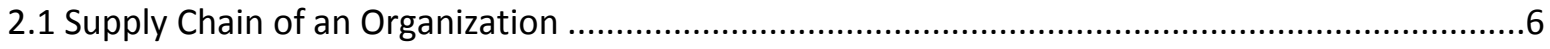

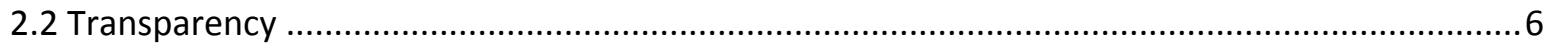

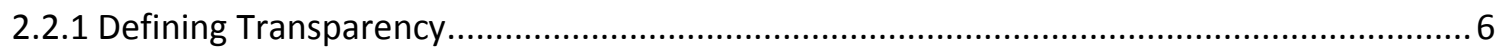

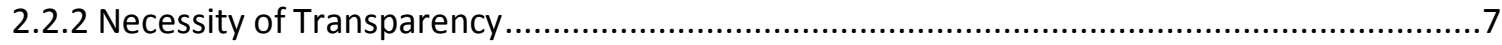

2.2.3 What are the Different Attributes of Transparency .......................................................... 7

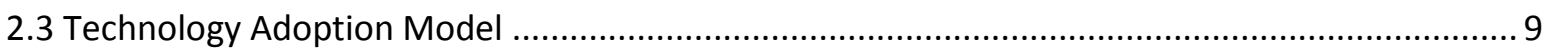

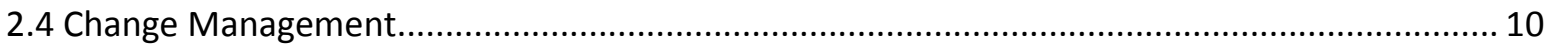

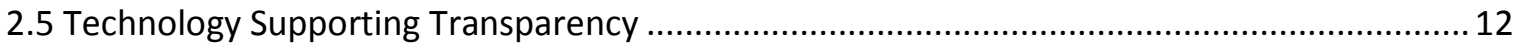

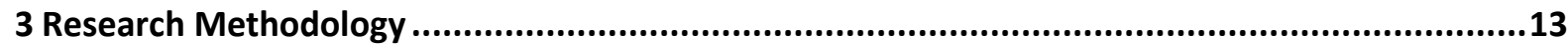

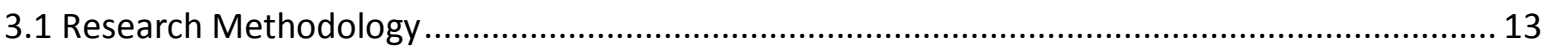

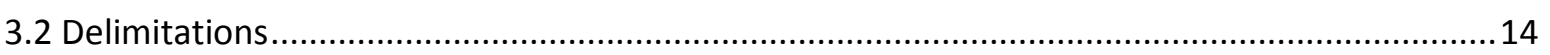

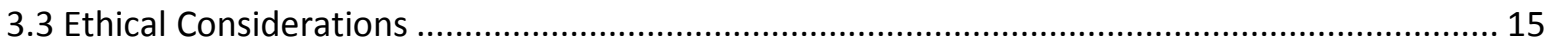

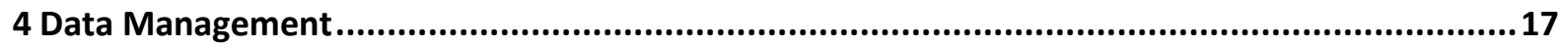

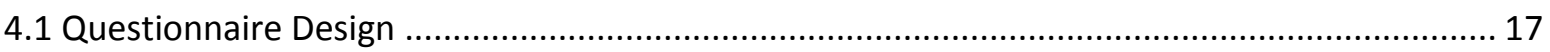

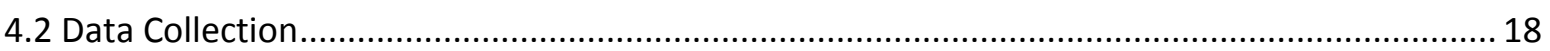

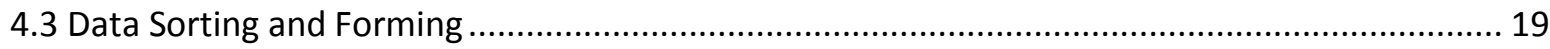

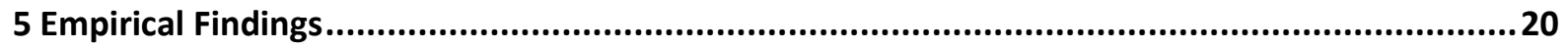

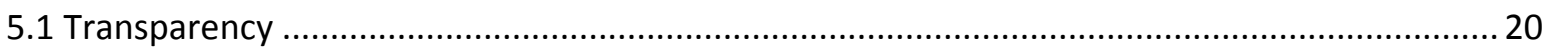

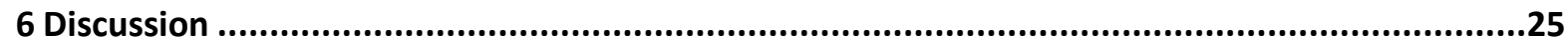

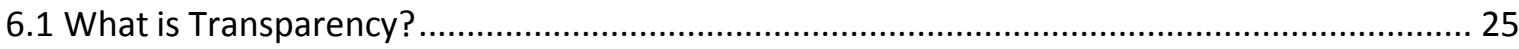

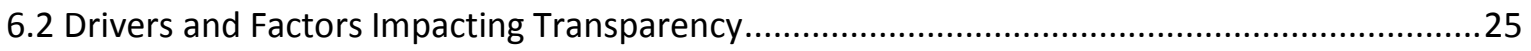

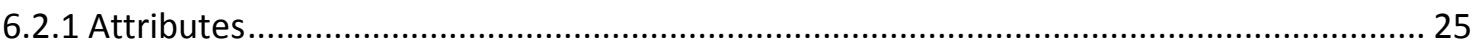




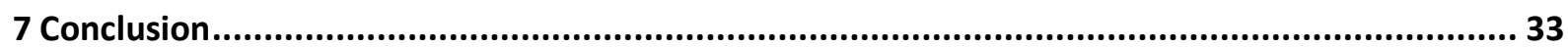

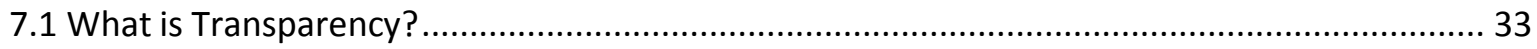

7.2 What are Key Attributes and Drivers of a Transparency? .........................................................33

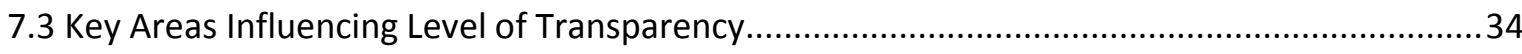

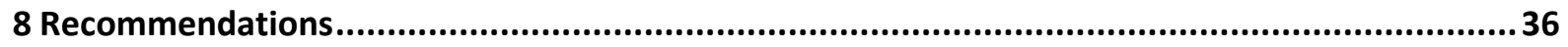

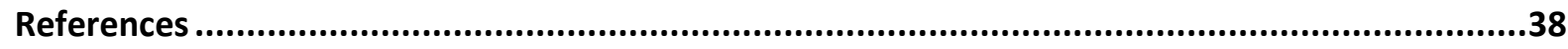

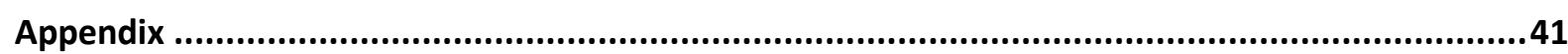

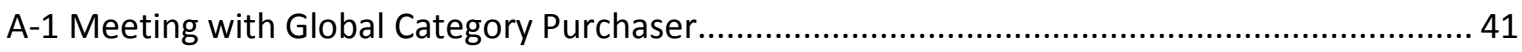




\section{List of Figures}

Figure 1.1: Survey on characteristics defining leading organization in next 10 years................2

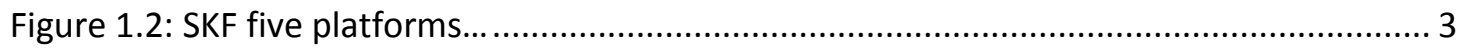

Figure 1.4: Supply Chain of a manufacturing organization......................................................

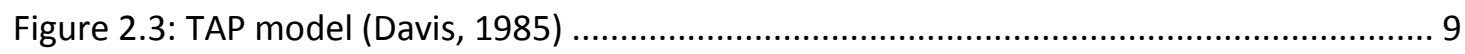

Figure 2.4.1: Dealing with people issues during change transf. (Hiatt \& Creasey, 2003)........ 10

Figure 2.4.2: Interrelations among the factors impacting change and critical stakeholders of change 11

Figure 2.4.3: The change process \& adjustment (Kubler-Ross, 1969, cited in Cameron \& Green 2004, p.29 and Gurler, 2010) .

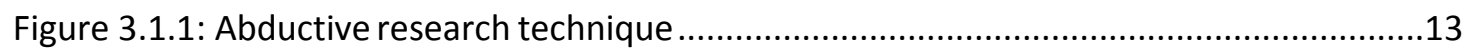

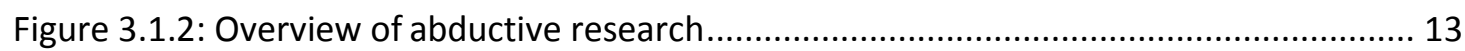

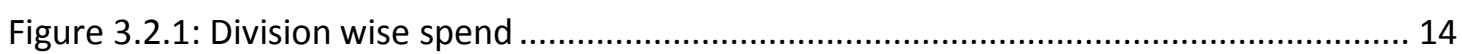

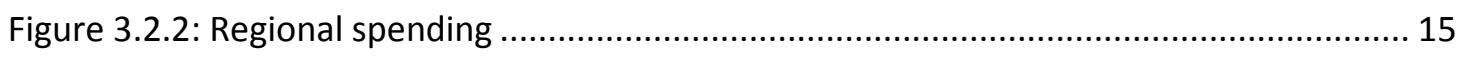

Figure 4.2.1 \& 4.2.2: Interviews- Experience representation \& Management position............ 18

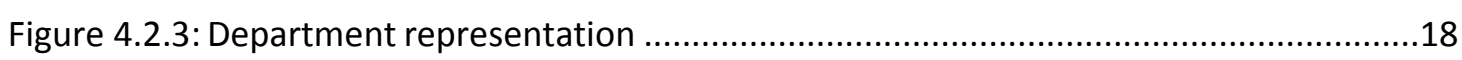

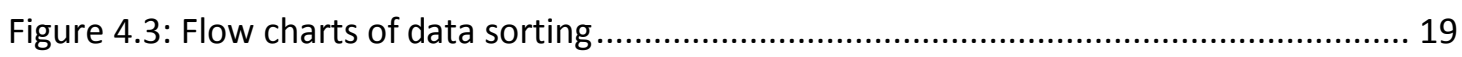

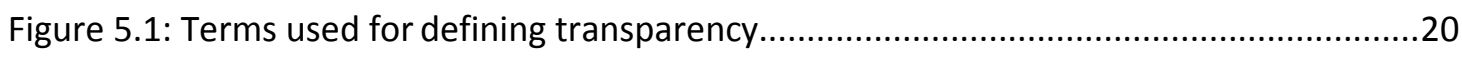

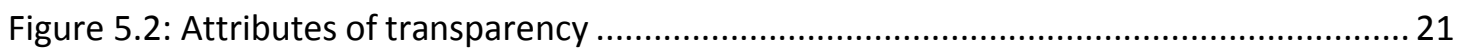

Figure 5.3: Respondents opinion on current \& desired transparency levels ...........................23

Figure 5.4: Cause and effect representation for lack of transparency..................................... 23

Figure 5.5: Interaction between key areas factors responsible for lack of transparency .........24

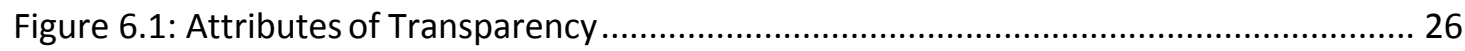

Figure 6.2: Key areas of focus in drive to transparency ..........................................................30

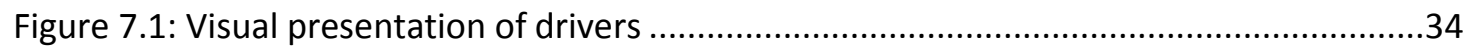

Figure 8.1: Path to increase flexibility for future adoption .................................................. 37 


\section{List of Tables}

Table 5.1: Key words used in describing what transparency meant .......................................21

Table 5.2: Factors driving attributes of transparency ....................................................... 22 


\section{List of Abbreviations}

$\begin{array}{ll}\text { FMCG } & \text { Fast-Moving Consumer Goods } \\ \text { H\&M } & \text { Hennes \& Mauritz } \\ \text { SKF } & \text { Svenska Kullagerfabriken } \\ \text { FLA } & \text { Fair Labor Association } \\ \text { TAP } & \text { Technology Adoption }\end{array}$




\section{Chapter 1: Introduction}

\subsection{Background}

The purchasing function forms the backbone of any organization including both private and public sectors. With almost $60-80 \%$ of the firm's product cost directly being impacted by the purchasing function, the amount of scrutiny and the need for its effective functioning becomes a key priority. It's predominant to understand what forms the entire organization function and their activities are crucial to driving effectiveness. The key to effective management is understanding, where synergies exist and how they work.

The need to know what's inside a product and how it has made has significantly shifted over years. Increase in self-awareness about individual social responsibility primarily due to change caused by the advancement in technology and the ability to differentiate between human and inhuman practices in developing and making a product (Young, Hwang, McDonald and Oates, 2009). Increasing awareness across the world on the need for environmental protection and sustainability has further strengthened the intent of customer to know how and from where a product is made apart from the understanding what a product contains. The trend started with internal awareness on the need to understand the side effects of the edible products and their composition on the consumer. This brought an obliged change in the FMCG sectors to provide a more transparent view of what and how a consumable product has made. A shift of this trend in the change in packaging labeling design of a packaged food over the past 15 years. The difference in labeling design gradually became a competitive factor for most of the food manufacturers because of the growing need among the customer to know and understand what a product is made off. Thus, initiating the trend of maintaining transparency in industrial sector particularly consumer edibles.

The trend slowly shifted to multiple industrial sectors, the immediate next one being the useable consumer products like clothing, apparels, and footwear. This trend started with the reports that most of the products like leather, silk is manufactured from animal extracts leading to exploitation and possible hunting of animals. That initiated the trend, where the origins of the product constituents were deemed mandatory. The discussion and need to understand how products were produced is an ever-present but gained voice because of significant incidents across the world; the most prominent of which is the one involving H\&M brand. The exploitation of cheap labor and inhuman facilities provided to them in Bangladesh has caught the eye of everyone across the world. This lead to a swift amendment in clothing industry practices in making their products more ethically and humanely. These change in perspective of humans has pushed the need for a more transparent way of working among many industries starting with food and clothing.

The shift in mindset was not only limited to this sector, but the need for establishing a transparent working has gained a voice in other industries as well. A recent survey by Global Scan on what would be critical characteristics that will define leading organizations in next ten years, transparency has featured as third most important thing after Sustainable strategy and Innovation as agreed by many experts across the segments (Global Scan, 2017). Another survey has found that $94 \%$ consumers indicate that they were more likely to be loyal to the brand, where $73 \%$ say they are willing to pay more. It also impacts internal employee motivation with most of them indicating that a transparent work atmosphere will boost their willingness to work (Alton, 2017). This shifting focus into supply chain transparency and its spread across the crucial sector of the manufacturing forms the baseline for this thesis research. The thesis 
research is carried out, based on a case study of a Global Manufacturing company, SKF AB being the one in our case.

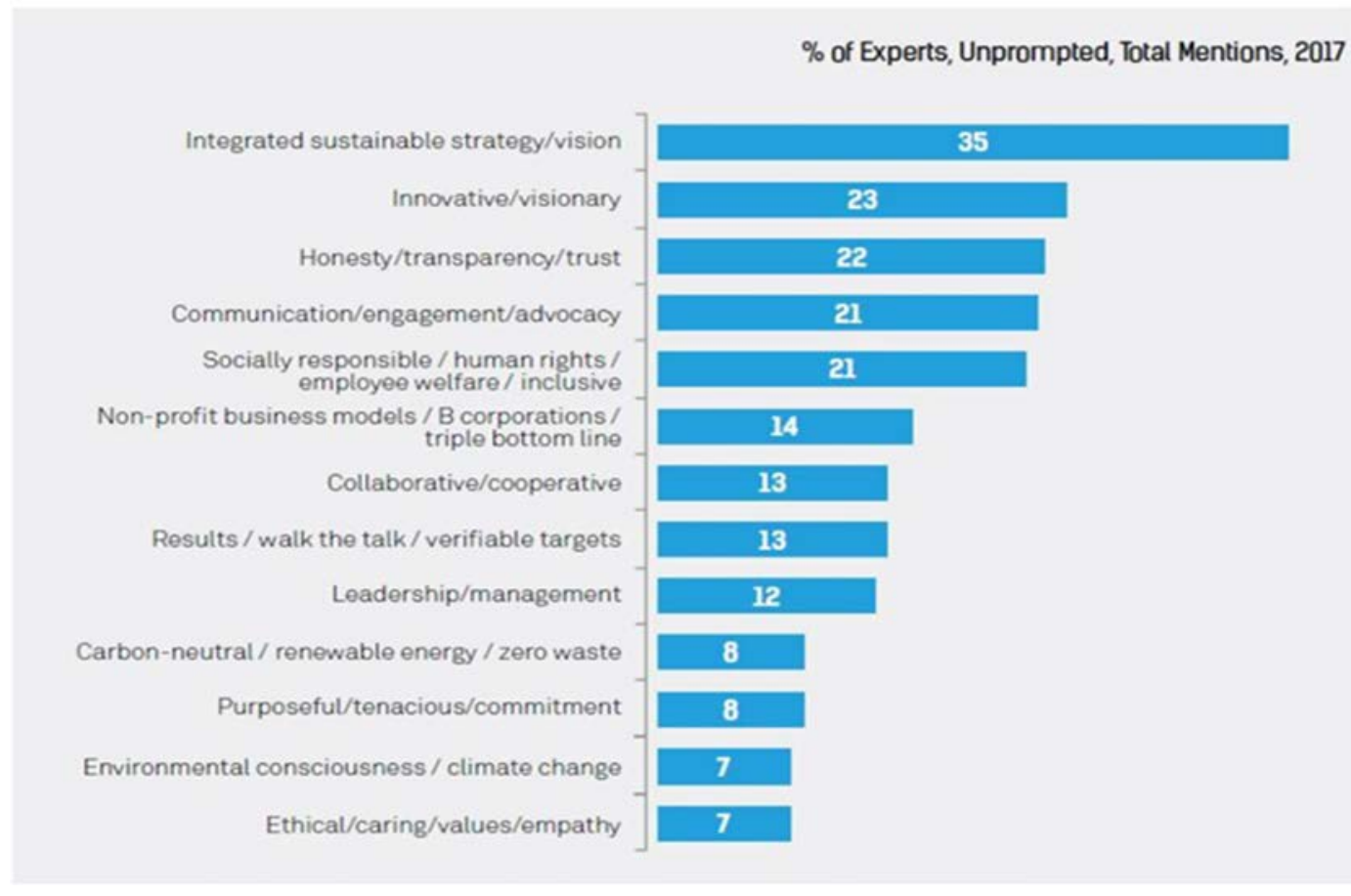

Fig 1.1: Survey on characteristics defining leading organizations in next 10 years.

\subsection{About SKF}

SKF (Svenska Kullagerfabriken AB) (English: Swedish ball bearing factory AB), later AB SKF, is a leading bearing and seal manufacturing company founded in Gothenburg, Sweden, in 1907. The company manufactures and supplies bearings, seals, lubrication and lubrication systems, maintenance services, condition monitoring systems, and related services globally. SKF is the world's largest bearing manufacturer and employs 40,000+ people in 108 manufacturing units. It has the most extensive industrial distributor network in the industry, with 15,000+ distributor locations across130 countries. SKF sells products within five technology platforms: Bearings and Units, Lubrication Systems, Services, Seals and Mechatronics (slowly coming out of it). SKF has been the market leader in the bearing industries supply among three different categories of Automotive, Industrial and Aerospace. The market position and technological superiority are evident by its market share of more an $75 \%$ in the aerospace segment and $100 \%$ in critical application within the sector. 


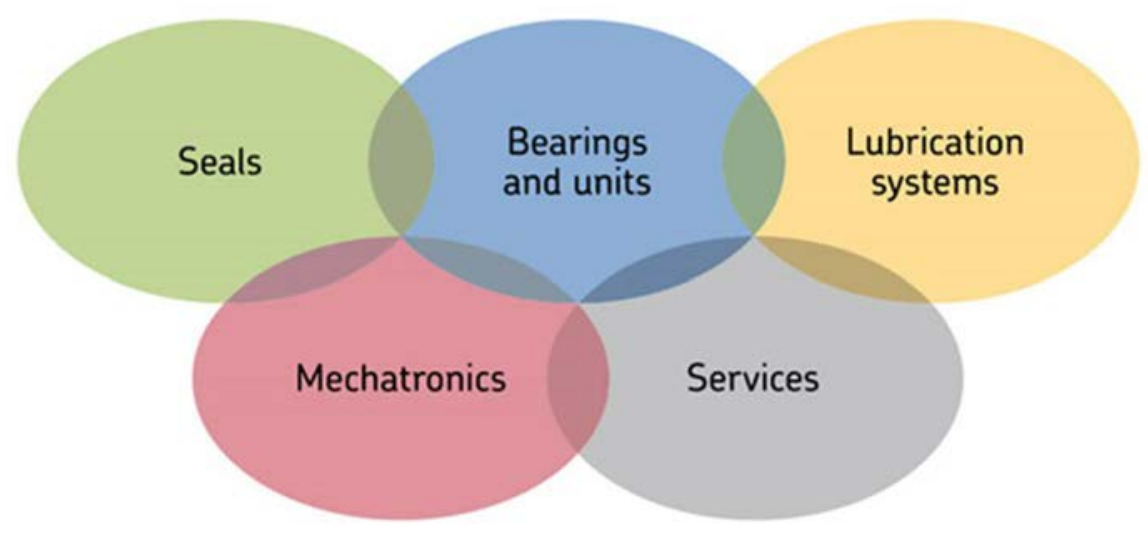

Figure 1.2: SKF five platforms

In Europe, SKF has a presence in all the countries with a majority of the factories located in Italy, France, Germany, Sweden, and Spain. The division caters to all the bearing needs in the European market with an annual spend almost to the tune of $50 \%$ of overall spend.

\subsubsection{Group Purchasing}

One of the critical verticals for SKF management system is their Group Purchasing division established to have global alignment in purchasing across the world. SKF Group purchasing was formed in early 2011 with most of the management team located in Europe. SKF purchasing was developed as the matrix organization with the focus on the Product Line Segments and Global categories for the key segments. The matrix organization is devised to assign a more aligned and synchronous purchasing practices with an equal focus on managing the product line needs along with a specific emphasis on Key categories likes rings, steel, balls, roller, and others. The Group organization management is formed with all the key PL and Global Categories come under the single head to ensure a quick resolution of the strategic conflicts and faster decision making. The purchase spends capacity of this global unit is in tune of 20 billion SEK.

\subsection{Aim}

With an increased focus on the need for transparency across the functions of an organization, the necessity to understand why transparency for a manufacturing company is predominant. Even though with much focus was placed over the last two decades by many manufacturing companies on the organization values and culture, forming a base to understand how transparency is defined and perceived within the organization. However, the authenticity and rightfulness of that meaning and its parallelism with the purpose of transparency seen outside the organization is essential. Two identical definitions and multiple perceptions about a single word could lead to misalignment in the strategic plans for the target market or industry as such. The main aim of this thesis research work is understanding what meaning of transparency is as perceived by multiple manufacturing organization and what common view that exists among all of them. In short, the thesis researches on understanding what the real meaning of transparency for manufacturing industries like SKF AB is. The thesis also focuses on the various aspects of Transparency in Supply chain and their impacts on the functionality of a long-term business plan. 


\subsection{Scope}

The scope of the thesis is to understand the definition and need for transparency in the Supply chain setup of a global manufacturing organization like SKF AB. The previous and ongoing research is more focused on understanding the aspect of transparency on general organization level and within the organization, but some of the supply chains are usually less prioritized or often not considered. The part being discussed here above is the upstream part of a supply chain which is generally outside the organization consideration mainly supplier and purchasing relations. Any discussion on supply chain would be incomplete without a proper evaluation of the upstream segment from the origin of raw material to suppliers till it reaches the organization for manufacturing the rest of the product. With the motivation to investigate the often less real aspect of the supply chain, this thesis research focuses on evaluating the transparency subject in a supplier purchasing relationship. The critical element of this study is understanding how transparency is perceived in the upstream segment with a more in-depth examination of the purchasing organization of a global manufacturing organization, the direct suppliers, subsuppliers and subsequent tiers.

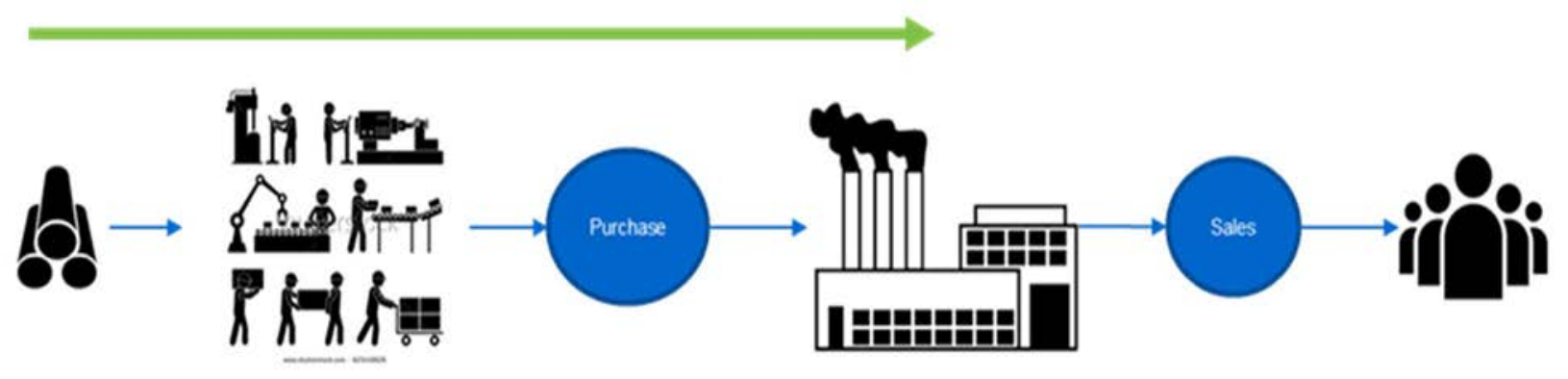

Figure 1.4: Supply Chain of a manufacturing organization

The scope of the thesis to thus focused on understanding the perceived meaning of transparency in a supplier purchaser business relation, the need for transparency and the factors hindering a more transparent purchasing \& monitoring process.

\subsection{Research Questions}

The theme of the research is positioned to understand, the overview and gain a general understanding of transparency in the upstream segment of the supply chain, which leads us to our first research question as below.

\section{RQ1: What is the definition of transparency in a supply chain?}

The word transparency is a very subjective somewhat objective, the definition of the word in modern context could be justified only by understanding the different attributes of transparency and what drives transparency in the business relation. These leads us to our second question for understanding the background in which the meaning of the word Transparency stands its ground. 


\section{RQ2: What are attributes and drivers of Transparency in a Supply Chain?}

Understanding the meaning of transparency could lead to the first step in creating a transparent business environment, but the effectiveness of the journey could be amplified by understanding the complexities and challenges involved in the drive. There could be multiple aspects or conditions which could define or restrict the level of transparency required. Establishing a general requirement for the level of the transparency needed would not be justified without understanding the actual needs and challenges involved with it. These leads us to question on identifying the critical problems and require which define the level of transparency.

\section{RQ3: What are key areas/issues which impact the progression of transparency?}




\section{Chapter 2: Theoretical Frame Work}

This section focuses on establishing different theoretical topics used for conducting the thesis research and set up a knowledge base on which the analysis is carried out. This section provides a general outline in gaining some basic knowledge about the theory that will be used in the study at the later stage.

\subsection{Supply Chain of an Organization}

The supply chain of organization can be perceived as an established setup which follows or monitors the entire process of getting raw material to actual conversion of it to the final product before it reaches the customer. Supply chain management is the systematical process of value addition where the main aim is to satisfy the customers both immediate and end, at the same time form a network across the whole organization to increase the efficiency and competence so that it can maintain its sustainability. Purchasing forms, the from the end of the supply chain and the product at the customer is the final part of the supply chain. For global organization supply chain is further divided into upstream which involves purchasing and suppliers and downstream, which include manufacturing and customer. A combination of strategies like Agile, lean is used to increase the overall efficiency of the supply chain. (Nel \& BadenhorstWeiss, 2011)

\section{$2.2 \quad$ Transparency}

\subsubsection{Defining Transparency}

Transparency is mostly defined by information sharing and disclosure of information (Albu \& Flyverbom, 2016) However, transparency can assume a contextual meaning based on the kind of information or data shared. The excess focus on the disclosure of the data has led to transparency to be perceived as extreme organizational behavior. However, transparency is not only an issue outside of the organization with its stakeholder but also within the organization with its internal stakeholders. Also, in sustainability, transparency is a highly expectable aspect. With the continuous push of stakeholders' sustainability, organizations have increased their focus in all departments' sustainability where "Supply Chain Transparency" has also gained prominence.

Most of the authors explained supply chain transparency as the "traceability" aspect where other authors care supply chain transparency as the "disclosing sustainability conditions" at suppliers. Here traceability means the capability to track the desired products' flow from its in-house to the outhouse. On the other hand, disclosing sustainability conditions at any specific supplier, it could be any disclosure- say for example for the complete factory audit reports multistakeholders' initiative for FLA (Fair Labor Association). Experts define supply chain transparency as a tool for the consumer and for the stakeholder for developing the potency of private regulatory systems such as codes of conduct and auditing. In another way, it is identified as a tool for shifting power from the disclosing firm to stakeholders. Additionally, experts define supply chain transparency as the corporate tool as well. Thus, it helps to increase the revenues from the company perspective. (Egels-Zandén \& Hansson, 2015) 


\subsubsection{Necessity of Transparency}

The World is changing rapidly, and these changes are happening in almost every sector in technology, environments, markets, organizations and so on, that is why the needs for optimizing the whole supply chain rather than the individual organization is increasing (Cao \& Zhang, 2010). However, in this era of globalization day by day, it's getting harder to keep track of what is happening in the whole supply chain system of an organization. However, over the past few decades, due to the push by the watchdogs and by consumers awareness to learn about child labor and other injustice muddled in the production of goods that they have purchased, now a day's companies are more conscious about the situation. They are trying to be more transparent and listing their supplier's name publicly which is one of their many steps. (Bain, 2018)

Earlier, materialistic and substantial distance detached supply chain upstream activities from the manufacturers and its downstream stakeholders. However, now the technology has kept the upstream much closer to the downstream stakeholders' consumers, regulatory agencies, media, non-governmental organizations, business customers and so on. (Bain, 2018)

However, it's not easy to achieve supply chain transparency when it comes to large organizations. Much dedication and at the same time solid foundation and continuous improvement is needed. (Deloitte Insights, 2018) However, the question comes why is it necessary to have a transparent supply chain in the organization? How does it impact the overall business? From the study that was done on Swedish Company 'Nudie Jeans' on a transparency project, the authors mentioned there that "Consumers do not leverage transparency, but that transparency improves consumer willingness to buy.” Additionally, the authors added that supply chain transparency is a useful corporate tool in practice. (Egels-Zandén \& Hansson, 2015)

Since supply chain management is the soul of any business so the more it is transparent, the more it is visible to its stakeholder. There is a great saying that "if you cannot measure it, you cannot manage it"- it's a piece of great advice for the managers who want to improve the overall business, and the same principle goes for the supply chain as well. Unfortunately, most of the organizations don't want to understand this, and they don't think till the transparency level. (Gattorna, 2003)

It's true that without the track and trace, the visibility of the entire supply chain management process is not possible and for that valuable information could be missed and affects the whole supply chain system. That is why transparency is turning day by day an essential potential for organizations so that they can learn from and act on supply chain information. However, it's not every time that the problem is lying in the manufacturing side or not; the consumers will criticize the end supplier disregarding of the real source of the problem. As a result, it is always better to take precautions rather than cures. (Anon, 2018)

\subsubsection{What are the Different Attributes of Transparency}

Now the question comes about defining transparency. What will be the characteristics that satisfy the level of transparency? How will the organization understand they have their supply chain transparent? Most of the authors who are supply chain specialists have mentioned so many elements but more or less all were pointing out some familiar and main characteristics. Four factors are meant to be the main characteristics of a transparent supply chain. They are- 
traceability, accountability, communication, and governance. These elements need to be present both in the upstream and downstream part of the supply chain.

\section{Traceability:}

(Sun, Wang \& Zhang, 2017) mentioned that it doesn't impact directly to the production system to progress instead it compiles information about product attributes and processes, facilitates contractual arrangements between companies and locates the contaminated product for recall when necessary though traceability can be identified as an apparatus to frame a fame for supplying high-quality products. However, traceability is essential for a number of reasons in a company or organization. Pointing out better sources of raw materials, acquiescing with international trade standards, accrediting credence facets- these are the main reasons, and all these reasons are because nothing but to have an overall transparent supply chain system.

\section{Accountability:}

It's not only the oversight of operations or accounting for results or impacts, but also other influences are there if we must describe accountability concerning transparency issue. Internal accountability and external accountability are another two dimensions that (Davenport \& Low, 2013) described. Internal accountability is when the organization itself is responsible for the implementation and completion of strategies and ideas and so on. On the contrary, external accountability goes to outside stakeholders as they are responsible externally for determining the standards of behavior. However, the authors also mentioned another kind of accountability, and that is strategic accountability. This accountability is for the impact of an organization's activities may have had on broad themes or strategies, but these all kinds of accountability is meant to have a transparent supply chain system. (Davenport \& Low, 2013)

\section{Communication:}

Probably one of the essential characteristics for being a transparent supply chain system. According to (Sayogo et. al., 2015), there have been several discussions how modern technologies are contributing to design and develop the information-driven supply chain, but at the same time, the level of adoption is not going in parallel which is an alarming matter.

It is beyond mentioning that open communication structure is very much essential for the companies or the parties those are involved in the close inter-organizational relationships, for instance, supply chain partnership. It's because the compact interconnection between the involved partners appear in several ways, media where communication channels must be well established and managed.

Besides, greater communication frequency is required to share more information jointly with the supply chain associates, and if there is superior coordination of activities, then communication will flow both upstream and downstream part of the supply chain infrastructure. As a result, supply chain partners will share more benefits and risks, and that would make both the parties involved in the supply chain even more transparent. (Cao \& Zhang, 2013)

\section{Governance:}

It's an essential characteristic of having a transparent supply chain. There could be several ways to enact the relationship between suppliers and buyers. According to the proposal of (Gereffi, 
Humphrey \& Sturgeon, 2005), a supply chain governance framework could be handy to seizure the applicable segments of buyer-supplier relations. Supply chain governance area is extensive, and it includes management of supplier relationships \& customer relationships. Mainly the spotlight would be the identifying the level of information sharing between a company and its different stakeholders. (Hofman, Beck \& Fuger, 2013) However, supply chain governance also includes corporate governance, business attributes, fundamental approach to an internal control system, making sure of everyone's responsibility, managing a business organization and so on. (Vasarhelyi, Chan \& Krahel, 2012) So, it could be beyond saying that how much essential it needs to be more transparent so that these whole supply chain governances would be more accessible and understandable for everyone including all the parties involved in the business for the sake of win-win situation.

\subsection{Technology Adoption Model}

Technology adoption differs on the size of the company because of its resource constraints. The difference of adopting level or the acceptance level of technology can make various possible opportunities or the benefits among the companies. These implementations of technology can provide immense competitiveness through the assimilation within different functions both inside the organization and outside as well with the suppliers or customers. The technology adoption influenced on several factors such as top managements' behavior, organizational culture, companies' resources, and products, government, relation both with the suppliers \& customers, external technology consultant \& vendors and so on. (Ghobakhloo, Hong, Sabouri \& Zulkifli, 2012) categorized these influencing factors on two different groups, external and internal. They further mentioned that outside group consists of the characteristics of technology products itself, external \& competitive pressure, external consultants, vendors, and government. On the other hand, an internal group made of top management's' behavior, companies' resources, organizational culture, and end users.

Two significant studies were carried to understanding what factors influence \& how they influence users' acceptance level when it comes to a question of technology or system or application. The initial study was done by (Ajzen a\& Fishbein, 2002) in their "Theory of Reasoned Action (TRA)" model and later the second study was done by (Davis, 1985) in his "Technology Acceptance" mode. (Ajzen \& Fishbein, 2002) emphasized user behavior in general whereas Davis explained with users' internal argument for acceptance of a certain technology or system or application. In TAM, Davis touched upon two things. One is user perceived benefit of users, and another one is user perceived ease of use which means Davis model is to cater a base for discerning the impact of external factors on users' internal factors.

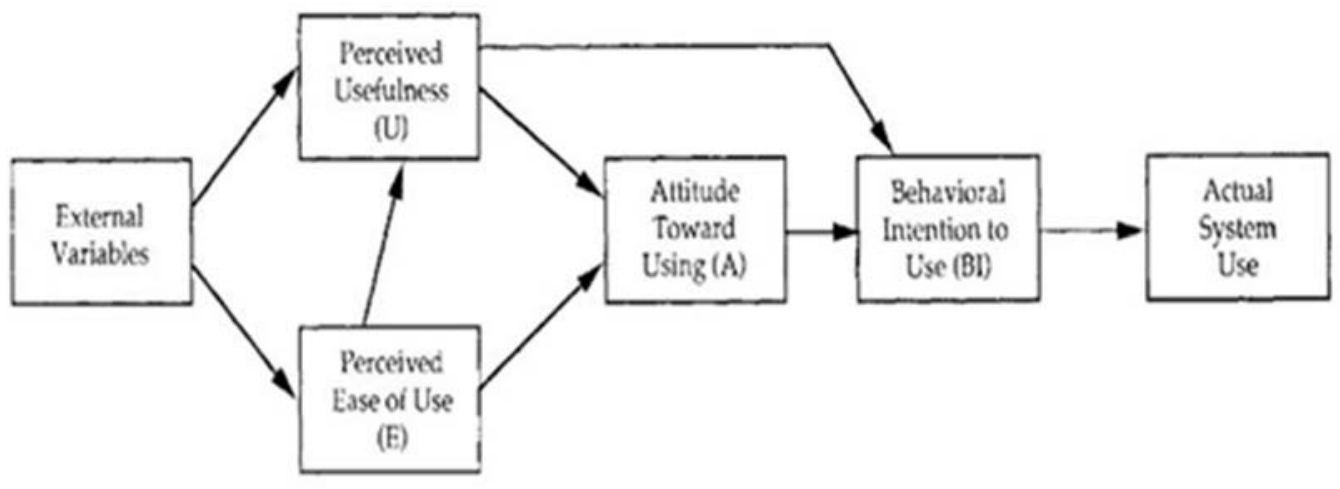

Fig 2.3: TAP model (Davis, 1985) 
Though (Davis, Bagozzi \& Warshaw, 1989) mentioned that user-perceived benefits have more impact when compared to user-perceived ease of use.

In the current century where the changeover is happening towards the global knowledge economy, research showed that information \& technology are looming as the new interpretive sources of productivity. The usage of internal competencies and aligning them external stakeholder competencies also becomes part of mutual technological adoption through coinnovation. Factual studies show that new co-innovation processes have been practiced mainly within large firms and companies. (Diaz-Chao, Miralbell-Izard \& Torrent-Sellens, 2016) mentioned that it is required to have coordination among the parties of co-innovation and the training among employers and employees. Besides, they also emphasized to correlate internationalization and productivity. The authors also suggested the necessity to contemplate the costs related to learning and implementing co-innovation practices. In these cases, public policies could be handy since it should be used to advocate sustainability policies to encourage change management over the times in the companies.

\subsection{Change Management}

There could be so many obstacles for making any successful changes. However, the question comes why there is need to happen changes. In this case, (Bridge, 1986) stated that evolution could occur when there is something, that needs to start, or there is something, that needs to stop. He further mentioned that change can still happen when something that used to happen in one way starts happening in another. However, (Bingi, Sharma \& Godla, 1999) Commented that practicing any arrangement is not a concern of simple adjustment of software systems, instead, it is more of an organization revolution. So, it could be said without any hesitation that change has a significant impact both on the organization and its people directly or indirectly. Even, this impact can apply to the job roles of one individual, their perceptions or this impact could bring changes to employers’ position or organizational structure.

However, it is obvious to mention that while occurring any change people associated with change needs to change as well to happen a successful change transformation. (Hiatt \& Creasey, 2003) emphasized in their article that a successful transition depends on both the business transformation or change, and people associated with it. Below figure demonstrates about it.

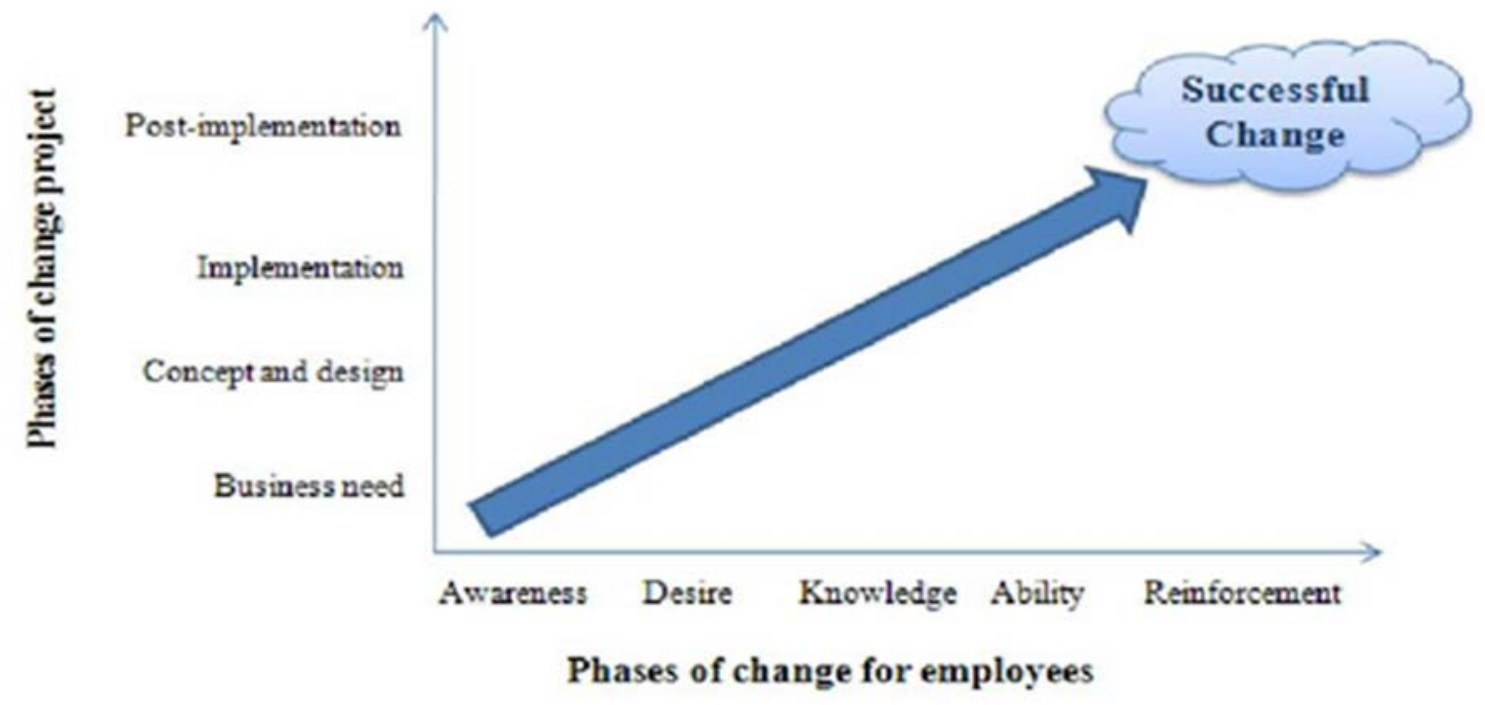

Fig 2.4.1: Dealing with people issues during change transformation (Hiatt \& Creasey, 2003) 
Besides, lots of authors have researched in their numerous articles about the obstacles and challenges that an organization face while implementing any change process where the change could be anything such as adopting any new technology or system or even any new organizational culture within the company. Though most of the obstacles or challenges are identified as success factors or influential factors when it comes to implementing if it often managed in a balanced way. Those are-

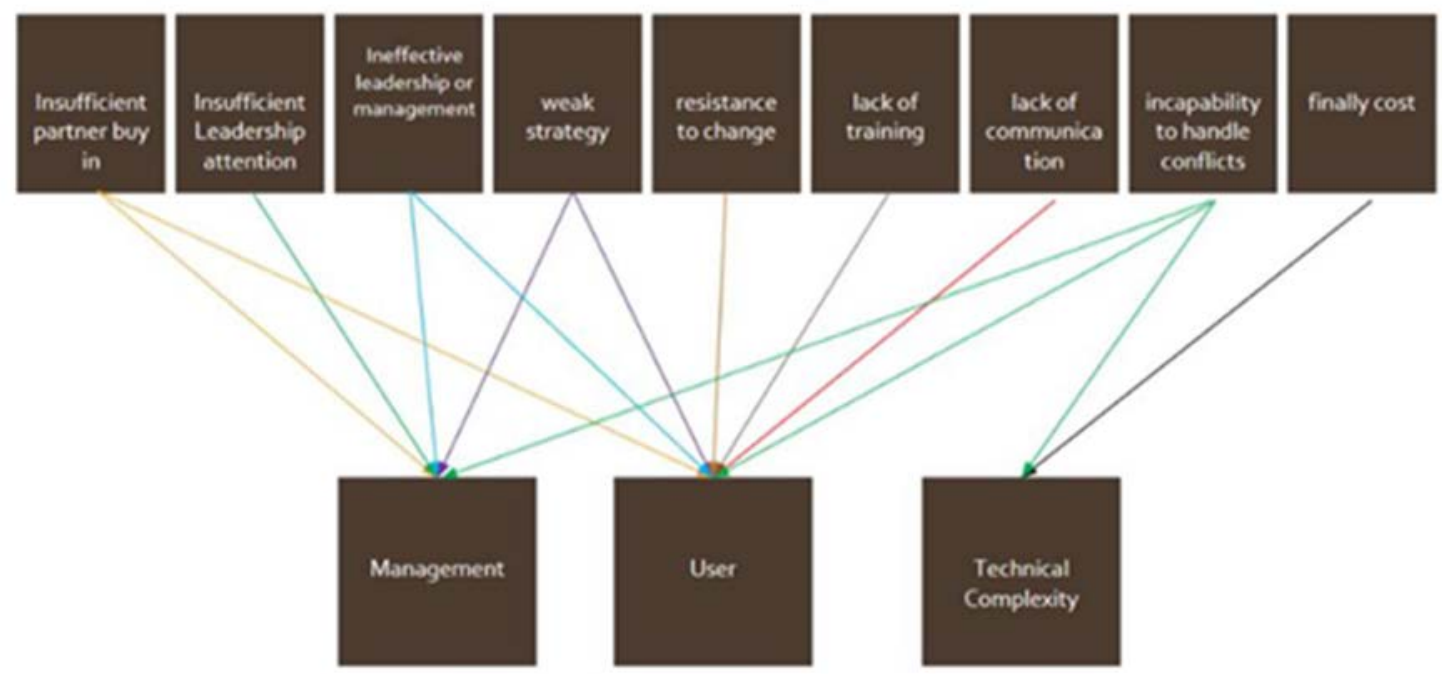

Fig 2.4.2: Interrelations among the factors impacting change and critical stakeholders of change

It is worthwhile to include that change is not always as smooth as it seen. So many obstacles can be operated from the user side himself or herself. (Kubler \& Ross, 1969) as cited by (Cameron \& Green, 2004) highlighted this subject matter. They introduced a time phase while the change process was occurring this on a psychodynamic path used to look changes on people with the terminal illness. Below figure shows different stages of people while happening any change. Based on studies on different organization changes and change in the behavior of user involved, they have identified that user in organization changes shows a similar shift in emotions and behavioral curves depicted below.

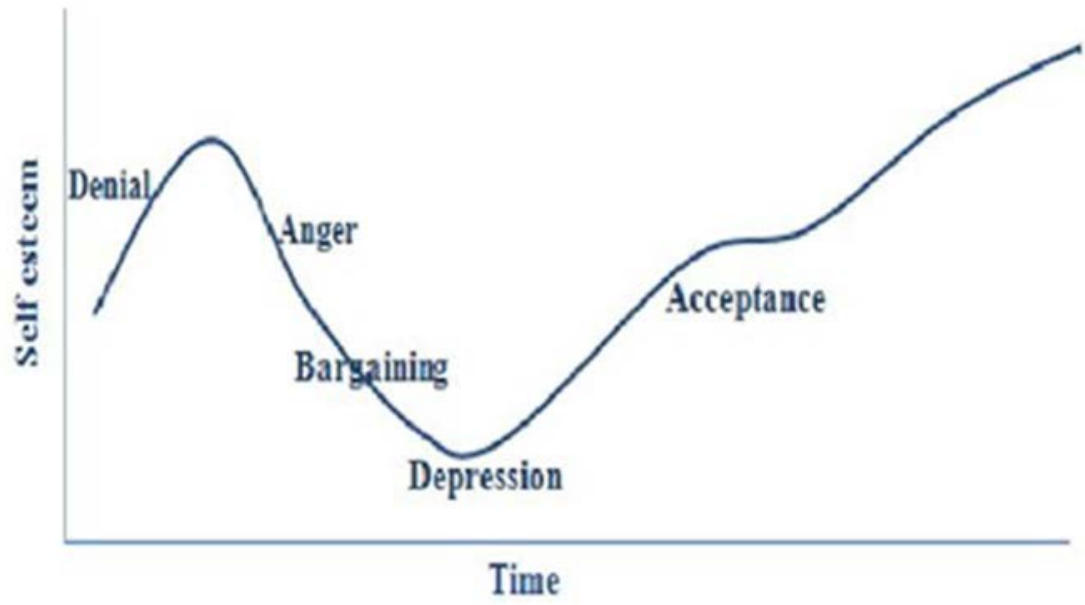

Fig 2.4.3: The change process \& adjustment (Kubler-Ross, 1969, cited in Cameron \& Green 2004, p.29 and Guler, 2010)

From the figure, some people could be in the denial phase by giving his or her maximum effort 
to prohibit the change. On the other hand, some accept the change and walk ahead with the change (Burke, 2002). Some show their anger and depression and try to resist the change by losing their value and existence (Pugh, 2007). Moreover, there are some other reasons behind it to oppose any form of variations. People fear to lose the status or power, also conflicting with their interest, cultural conflicts could also be the reason behind it (Trader-Leigh, 2002). Above all the ideas could the potential reasons behind the reasons for resisting any forms of changes from the people themselves. However, the question is- does the organization thinks all these kinds of factors before implementing any change.

\subsection{Technology Supporting Transparency}

The consumers have become more conscious about the transparency issues. "Consumers have become more concerned with the health, quality and ethical responsibility of their purchases"Guy Escarfail, Vice President SGS Transparency. (Davies \& Gutsche, 2016) The age of Transparency- With consumers demanding more detailed product information, new technology can help transform processors' operation- Debra Schug, Editor in Chief Partially, the recognition of the need for the transparency relates to the issue of validity. However, the question always comes debating how much the slide is required and also what would be the benchmark to use the technology for being more transparent. (Smythe \& Smith, 2006)

Besides, the market is becoming more and more competitive, and as a result, new threats are stemming due to lack of transparency. Initially, the supply chain was meant for delivering goods, but from the past decade, it's beyond just providing goods. Now its managing other flows as well such as the flow of money, flow of information, tracking down the goods, the origin of the products and so on. In short, it's all about being more transparent and need quick actions rather than slow flow so that the business can run more smoothly. These types of significant challenges can be mitigated by implementing modern technology concept and BLOCKCHAINa kind of distributed ledger technology can be helpful in this aspect. From the authors- Blockchain is a data structure format that makes it possible to create a stack of existence with a specific time stamp for each digital asset. The main convenient part of Blockchain is the users of it are allowed to share assets or equity without considering thinking that how to safeguard them. As a result, the trust is gained between the parties and that enlarges the level of information and coordinating and makes the environment as win-win situation among the related parties. It is said as the next industry innovation where the concerned supply chain parties can introduce in the system as a co-innovator since it is identified as the core element of modern development methodologies. (Eljazzar, Amr, Kassem \& Ezzat, 2018) 


\section{Chapter 3: Research Methodology}

This chapter establishes the methodology adopted for conducting this thesis research. The chapter also highlights the rationale behind choosing the research method and explains the ethical consideration taken for performing the thesis research. The last part of the section introduces to how collected has been managed and formed and will use in the subsequent stage of discussion and analysis.

\subsection{Research Methodology}

The two main qualitative techniques implemented for this research project are a survey and interviews. The approach laid out for this thesis is using interviews as a technique to accumulate general stakeholder observations. The observation would be used to develop general themes among the data and frame broad and general opinions on various aspects of transparency in Supply chain for manufacturing companies. The general ideas are then evaluated using the surveys to formulate coherence of the stakeholders and generate a base for the action research to conclude the investigation. The survey results would be used to evaluate the general themes by which the answers to the research questions are formulated through brainstorming by research students, and the participant from the organization is being studied as a case - this form of concluding research finding based on the strategy called action research.

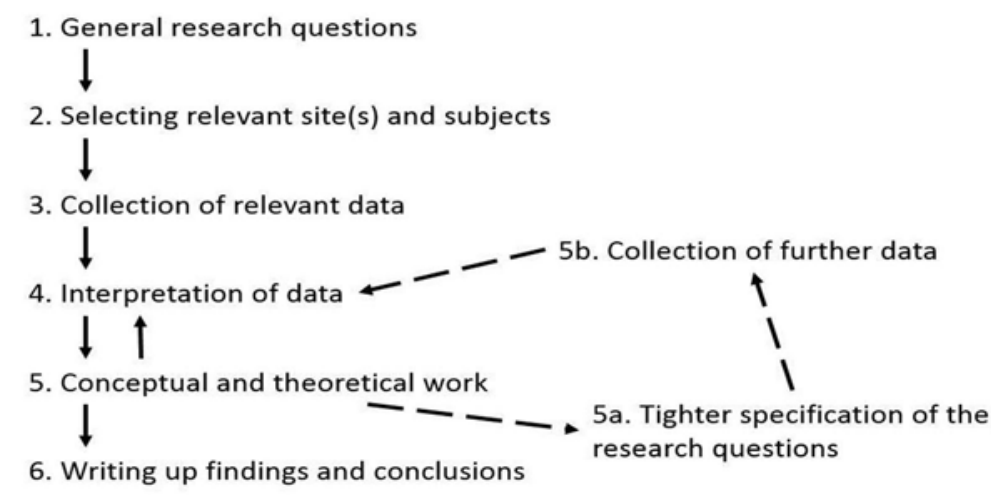

Figure 3.1.1: Abductive research technique

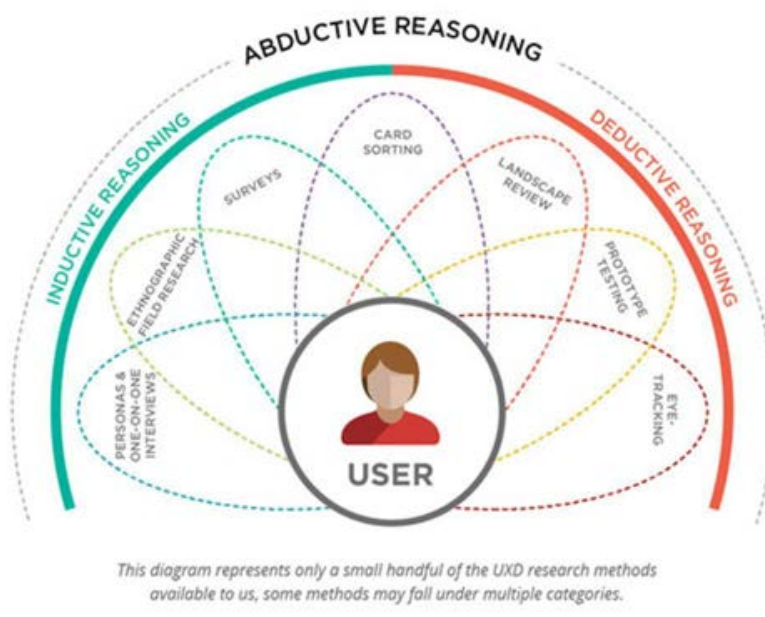

Figure 3.1.2: Overview of abductive research. 


\subsection{Delimitations}

The central theme of the research is to understand the subject of supply chain transparency in manufacturing industries. The initial discussion on the topic, the research was covering the entire supply chain from the origin of material till the final product moves outside the organization premises. Since the length of the research was expected to last for 20 weeks and on the evaluation of the prime need to stick to the scope, the research was limited to the upstream side of the supply chain. The call was also taken based on the understanding that a parallel effort is being placed within the organization to synergies various functions for effective internal handling. With the inclusion of numerous constraints and subject's value to the research, the research has been limited across several fronts. The details of which are as detailed below.

In the upstream segment, the purchasing is categorized into two major buying segments, namely direct (with five aligned segments) and indirect materials. In consideration with the time frame and value analysis of the segments, a decision was taken to focus on direct material which has a more significant impact on business operations both strategically and financially as can be seen from the figure below. Even though the spend on indirect was more, the strategic implication or effect on the final product was found to be minimal. However, a case of transparent purchasing system is implemented for the indirect material segment; namely, SAP Ariba would is studied for developing insights and learning of the system which could be applied to direct materials.

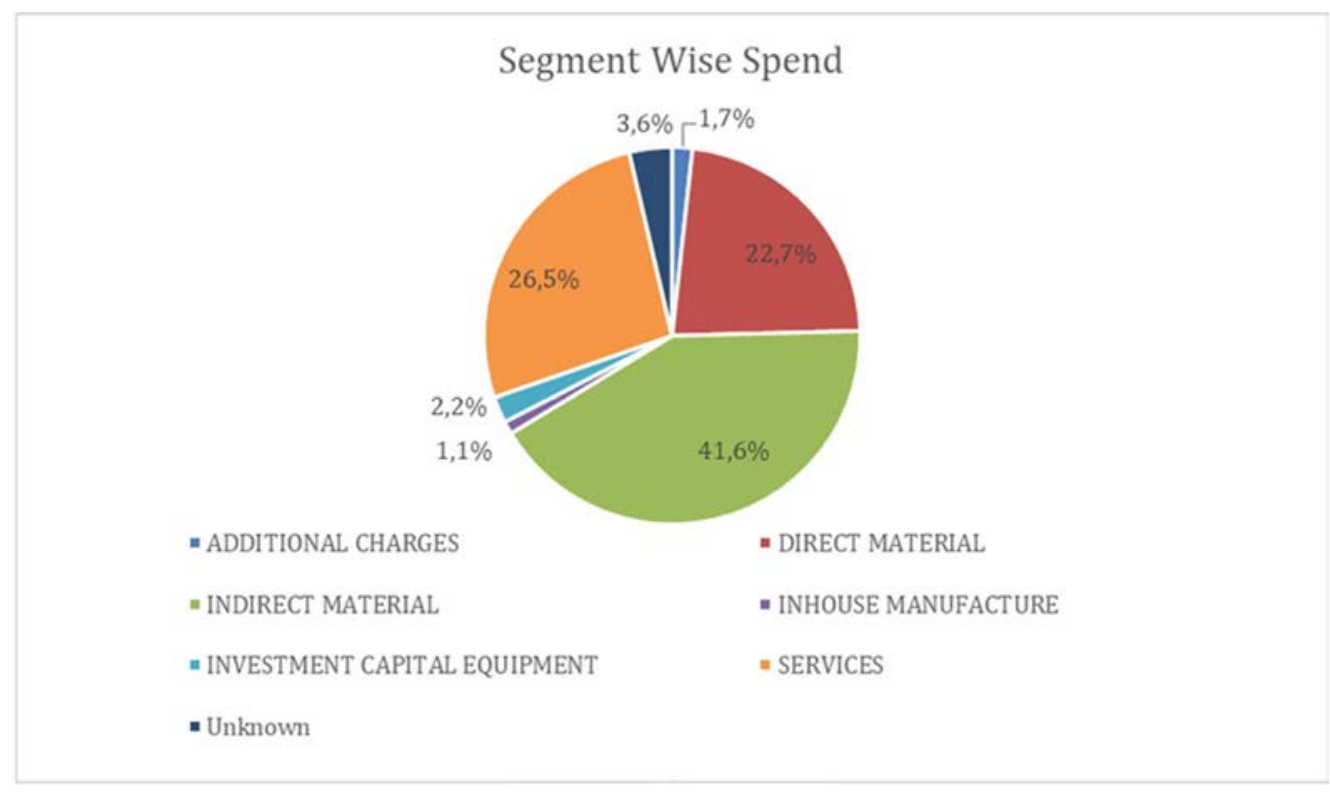

Figure 3.2.1: Division wise spend

Within the direct material segment, in consideration with geographical constraints and buying power of the factories across the world, the focus of the research has been restricted to the only European region. The regional wise analysis of the spent could exemplify the main contribution of European factories to total spend. 


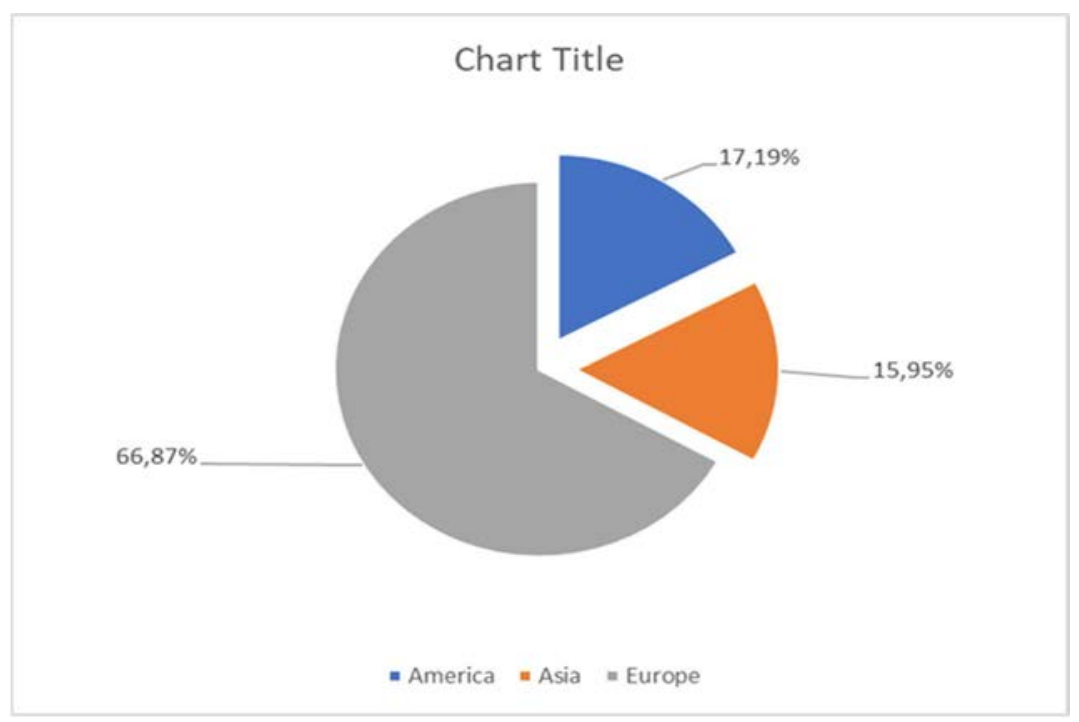

Figure 3.2.2: Regional spending

The research scope for the thesis is to understand and identify the most acceptable definition of transparency for all stakeholders involved in the manufacturing supply chain. Even though the details of the different factors affecting and defining the level transparency is evaluated, the root cause analysis and measurement the depth of the impact fall outside the thesis purview. The research touches upon the various technologies and learning that could enhance transparency. However, an in-depth analysis of how the technology will be useful and where it needs to applied is excluded from the research scope.

The approach established for conducting the research, include interaction with various suppliers and sub-suppliers to gain a broad perspective. However, in consideration to the timeline, practicality involved, and strict rules laid by SKF, the supplier how would be interviewed will be limited to a few specific ones suggested and introduced by SKF. Even though an SKF decides on the suppliers, the choice of the researchers was made available to SKF for better selection. The tier 2 and below suppliers are excluded from the research purview, but few examples of them would be used during discussion part of the report.

\subsection{Ethical Considerations}

The research study includes interviews, and hence all the ethical practices related to interviews and data collection would be applied. The ethical considerations for the research aspects is detailed under four main ethical concerns and how they are maintained during the research duration and after.

a. Harm to Respondent: As most of the research data is around the sensitive subject on communication and sharing of information across the organization and outside, the sensitivity of information gathered has roused multiple fronts which could lead to complication. The content and content provider details have been kept anonymous from other apart from the researchers. The information gathered is stored within the computers of the researcher with restricted access to others. The information is not placed in the online storage sites like Google drive or One drive. Steps have been taken to ensure the data is kept safe and all the interviewees were 
informed on the handling of data for the research and how data would be destroyed post research.

b. Deception: No amount of fraud was used during the process. The data collected only through the consent of the stakeholders and no deceptive or covert means are used to obtain data. Any data found externally from others about any stakeholder was verified with them if we find the data would be useful. The wrong interpretation of the data was avoided to the maximum extent. However, in the case of data where there was a lack of clarity, the stakeholder was approached to gain clarity.

c. Lack of Consent: The interviews are booked in advance, and the purpose of the interview is shared with the interviewee before the actual interview is conducted. The details regarding how the data collected would be used, is shared with the interviewee. The interviewees were informed, and consent was taken before the start of the interview about using phone recorder. The transcripts of the data collected were provided at the end of the interview and consent was taken to use the information.

d. Invasion of Privacy: All the personal related questions are avoided to the extent possible. The interviewee was given time to think for framing the response and care was taken to avoid external stress or extreme probing which would have left the interviewee in discomfort. Care was taken to ensure the interviewee identity would be revealed after the consent was obtained and approved to which the only one agreed. Thus, the whole report the respondent or interviewees would be, and his last name would call the one interviewee who has given his consent use. 


\section{Chapter 4: Data Management}

The data for the research was obtained by conducting interviews and surveys with multiple stakeholders involved in the upstream part of the supply chain. The interview questions were designed in advance to the meeting based on select criteria, further detailed in this segment. The survey will be used as the second resource for data collection. The survey would be developed based on the observations from the interview responses, the details of which will be explained below.

\subsection{Questionnaire Design}

The framework for the questionnaire is set by categorizing questions across five sections. The structure was adopted to ensure data generated was aligned to address multiple theory aspects studied. Most of the question framed were closed questions. However, quite a few open-ended questions are framed to understand the broader perspective and provide opportunities for discussion.

The first sections include the question to gather information which could be used to understand the background of the interviewee. The details are collected to understanding how educational background and work exposure could affect the interviewee's perception and logical understanding in adopting the concept of transparency in work. The questions are framed to understand the roles and responsibilities to frame follow up a question in understanding the intricacies in stakeholder management and the need for effective communication.

The second section of the questionnaire includes questions to framed to investigate user opinion about the subject topic. The sections also try to understand the interviewee's direct experiences about benefits and backdrops of transparency in a supply chain in their current roles and previous roles. The questions are designed to gather recent experiences and examples where transparency could be the significant factor. The question also forms the base for the next section of questions as well as to frame follow up a question in the next section and investigate further on the examples quoted.

The third section includes questions which could provide insights into the efforts and steps taken by a manufacturing company related to work on their internal transparency. It also includes some questions to gain insight into cross-functional working or collaborating aspects within a manufacturing organization, where transparency and communication are significant parameters. The section tries to bring light on the expectations of employees within the organization to understand the governance aspect of transparency.

The fourth section includes questions which could provide insights into manufacturers expectation on transparency from the suppliers. This section tries elite information which could define the transparency needs in an effective supplier purchaser business relation. The section also seeks to understand what measure SKF or as such a manufacturing company needs to be placed by an organization for enhancing the efficiency of supplierrelationships.

The concluding section tries to gain to interviewees the last opinion on the certain set of aspects in evaluating the current position. The questions are tries to identify the areas which we could have missed in completing the research.

The example of one the questionnaire conducted for a Global Category purchaser for a segment 
is attached in the appendix A-1, the follow-up questions in the interview process are detailed in appendix A-2.

\subsection{Data Collection}

The data collection for the research was primarily through qualitative interviews with members of SKF and other agencies with direct relevance to the aspect of the study. The interviews were taken on candidates chosen from the carefully selected list of the SKF group purchasing and institutions working on procurement related research. The selection of the meetings was based on the geographic presence, position in the organization chart and their work role contribution to the purchase spend. As the thesis research is focused on the European region and its biggest spenders in the area as detailed in the chart below. The interviewees selected forms a mixed group with experience level ranging from 1 year to 25 years across the organization structure.
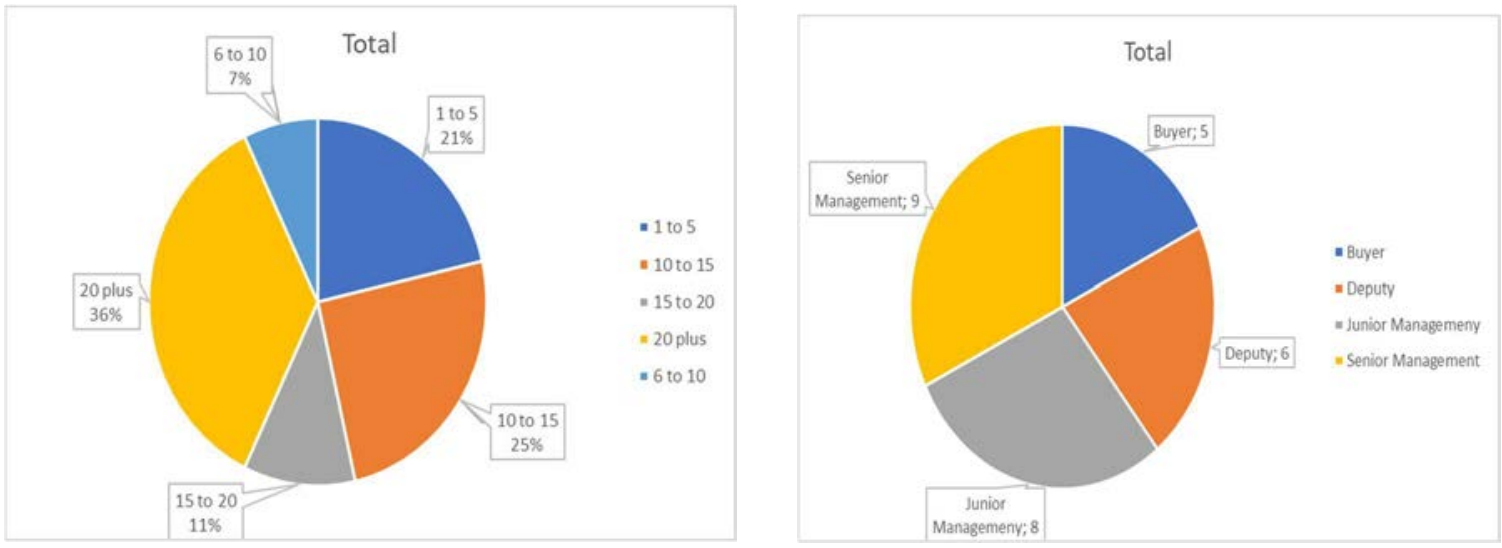

Fig 4.2.1 \& 4.2.2: Interviewees-Experience representation and Management position

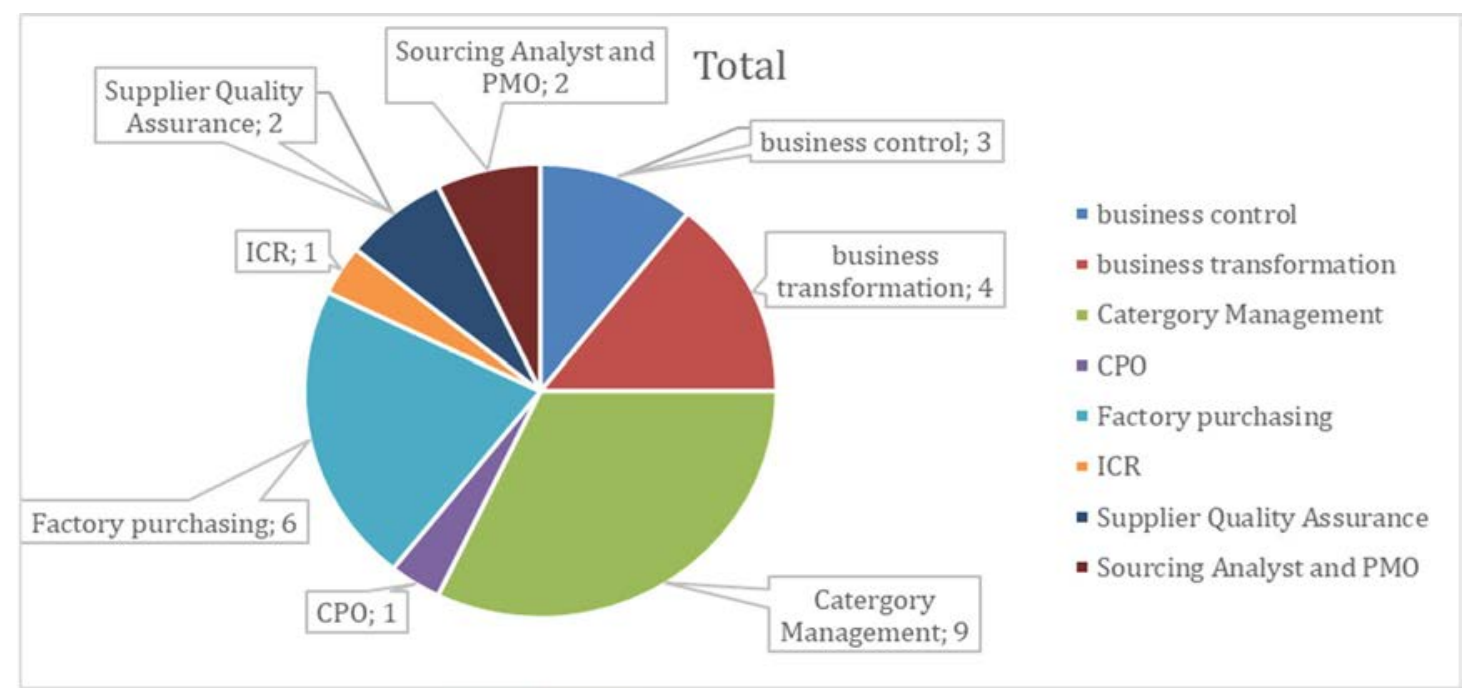

Fig 4.2.3: Departmental representation 


\subsection{Data Sorting and Forming}

The qualitative data collected from the interviews are separated into various subsection based on the aspect being discussed in the interview. Every interview is designed to collect data on specific themes and the data collected is segregated and placed in the same theme. In some specific themes like root causes, further subsections are created to gather and optimize data as much as possible to create a various hypothesis. The data collected in the themes and subsection were selected and assigned a frequency rating, based on the recurrence of the same aspect from different interviews. This system was created when opinions of the interviews are collected for open questions for example; when data is being gathered on understanding SKF's perspective of what the definition of transparency is. Transparency is a subjective term based on the situation and the context in which the discussion took place; scenarios are noted down to be used during the analysis phase. These recurring themes are then used to compile a holistic and popular terminology used for defining transparency for SKF. The themes, particularly for the root causes section has been later merged and discussed in conjunction as most of the root causes are related to one other. Fishbone and action research is used to find the recurrence and understanding the issues which are the cause of others. The data sorting and division of themes is based on the flowchart detailed in the figure 4.4 below.

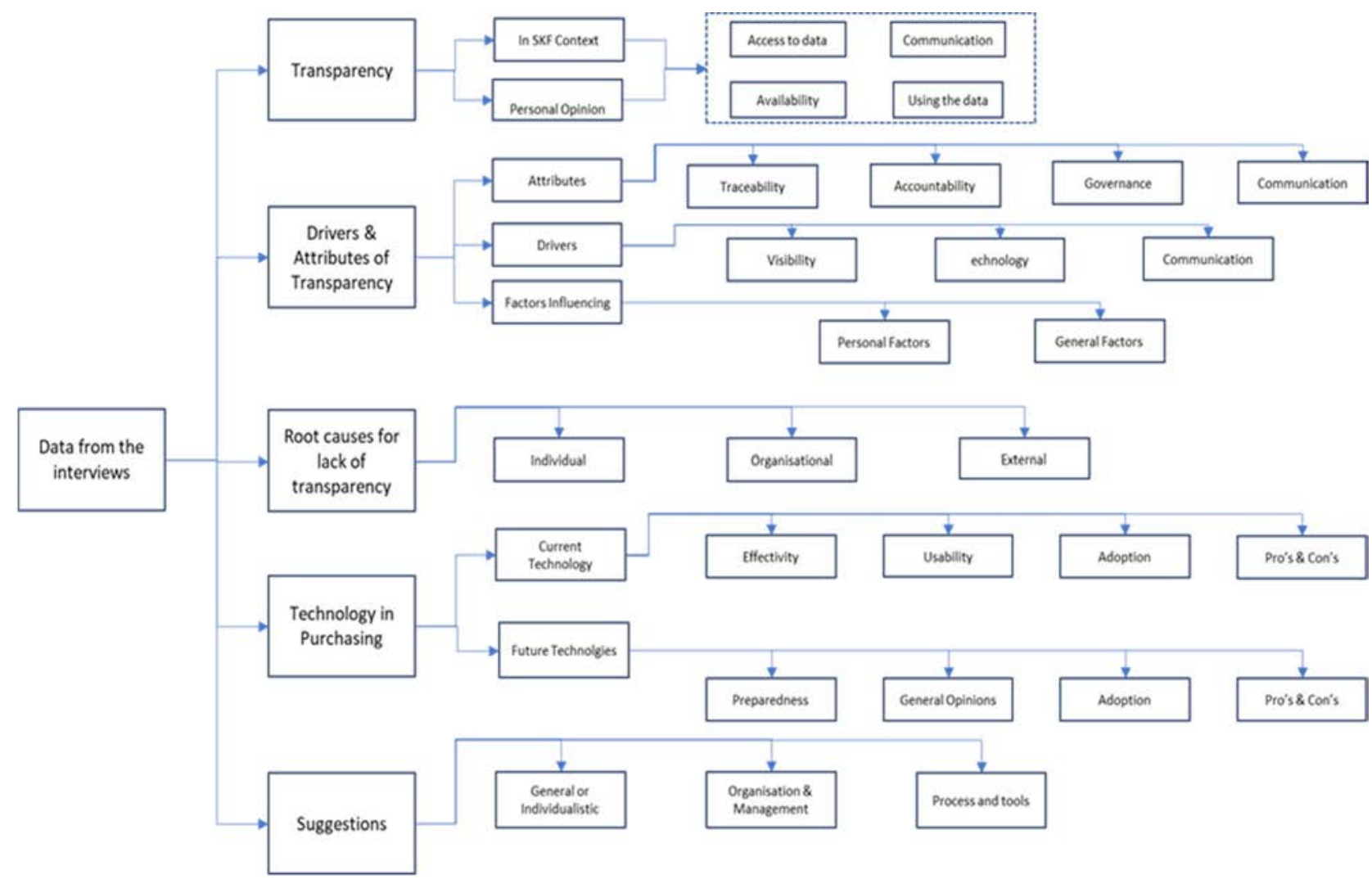

Fig 4.3: Flow charts of data sorting 


\section{Chapter 5: Empirical Findings}

This chapter details the findings from the qualitative interviews. A sub section presents the data related to the various aspects discussed in the qualitative interviews for answering the research questions.

\subsection{Transparency}

The data findings presented here, are the opinions collected from the various interviews conducted at SKF. One of the main questions asked during the interview is the respondents perceived the meaning of transparency. Considering the subjective nature of the word "transparency," the respondent was asked to explain his perceived meaning in two different subjects a). General perception b), in their work role. The various definitions by the respondents have been used to find the keywords used as shown in table 5.1. The respondents have quoted six popular keywords in their responses to the perceived definition. The number of mentions of these keywords is as shown in figure 5.1. All 30 respondents have used the term data and information both in their general and work perspectives whereas the word documents/ documentation/ contracts have been used less in overall. The number of mentions for documents in the work environment is comparatively more but still less popular.

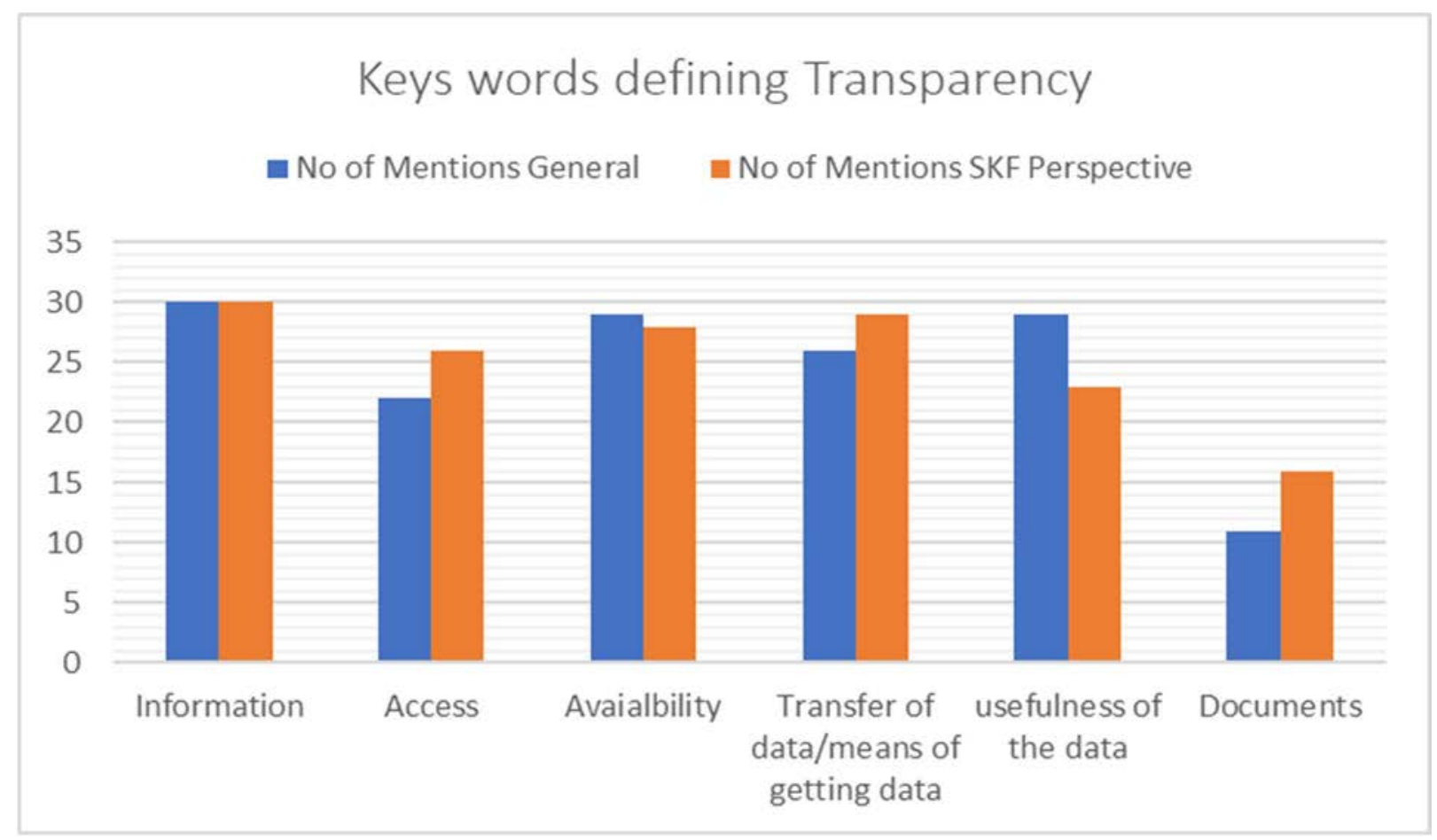

Fig 5.1: Terms used for defining transparency 


\begin{tabular}{|c|c|c|}
\hline \multirow{2}{*}{ Key Words } & \multicolumn{2}{|c|}{ No of Mentions } \\
\cline { 2 - 3 } & General & SKF Perspective \\
\hline Information & 30 & 30 \\
\hline Access & 22 & 26 \\
\hline Availability & 29 & 28 \\
\hline Transfer of data/means of getting data & 26 & 29 \\
\hline usefulness of the data & 29 & 23 \\
\hline Documents & 11 & 16 \\
\hline
\end{tabular}

Table 5.1: Keys words used in describing what transparency meant

\section{Attributes of Transparency:}

As with generating a holistic definition of transparency is important, finding the characteristics of transparency adding a more subjective perspective. The next set of question used to analyses the different characteristics of transparency has been tabulated and plotted as in fig 5.2. The various attributes are different things which come into their mind when discussing a transparent environment. The different characteristics are collected based on the respondent's perception of what is essential for a transparent working environment. Openness and traceability are two characteristics which were highlight by most of the respondents, whereas the characteristics ownership and control has been mentioned or discussed the least number of times with a mention of 3 and 5 times respectively. The characteristics openness is explained by most as an environment where the hindrances to share or get any information is minimum. The traceability is described as the need to know the path in which the data is available in the current form. It was discussed the most as most of them felt, understanding the formation of information or data from the source level enables the respondents to take better decisions and to ensure the downside effects of a wrong output is minimal. The other essential and prominent characteristic defined by the respondents is the ability to access any desired information and understanding the presence of specific data. These two were explained to improve the ability to quicken up the process of decision making which is holistic and adds value to the organization.

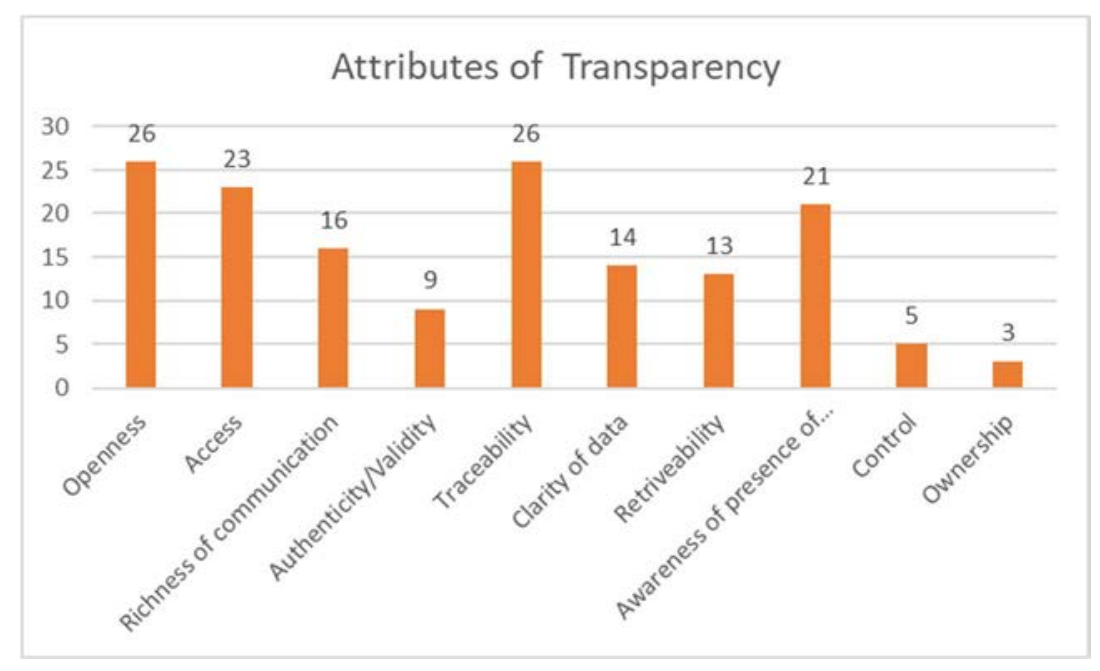

Fig 5.2: Attributes of transparency 


\section{Drivers of Transparency:}

The understand the transparency in a better manner; it is essential to understand what drives transparency forward. With no formal identification of direct drivers as possible, the data presented below shows the drivers of the characteristics of transparency which boosts the overall transparency level in the organization's function.

The drivers of the transparency come from the main aspects in a transparent environment. The direct effects of these drivers to the different characteristics have been formulated based on the respondents understanding. An approach was adopted to form the relationship matrix based on the consensual agreement among the respondents. A yes is where more $70 \%$ of respondents agree a formal relationship exists between the attribute and the driver. NA was used where the agreement from the respondents is less than 30\%. Maybe it was used where the consensus among different stakeholders is between 35\% and 70\%. The plotting of the relationship between the attributes was the tabulated as shown in table 5.2 and discussed with SKF team to ensure the validity of the observations.

\begin{tabular}{|c|c|c|c|c|c|c|}
\hline \multirow{2}{*}{ Attributes } & \multicolumn{6}{|c|}{ Drivers of Attributes } \\
\hline & Location of data & $\begin{array}{c}\text { Availability of } \\
\text { data }\end{array}$ & $\begin{array}{l}\text { Technology } \\
\text { Availability }\end{array}$ & $\begin{array}{l}\text { Technology } \\
\text { Useability }\end{array}$ & Communication & $\begin{array}{c}\text { Competence to } \\
\text { use data }\end{array}$ \\
\hline Openness & Yes & Yes & Yes & Yes & Yes & May be \\
\hline Access & Yes & NA & Yes & Yes & Yes & May be \\
\hline $\begin{array}{l}\text { Richness of } \\
\text { communication }\end{array}$ & NA & NA & Yes & Yes & Yes & NA \\
\hline Authenticity/Validity & NA & NA & Yes & Yes & May be & NA \\
\hline Traceability & Yes & Yes & Yes & Yes & Yes & YES \\
\hline Clarity of data & NA & NA & May be & Yes & NA & YES \\
\hline Retriveability & Yes & Yes & Yes & Yes & Yes & YES \\
\hline $\begin{array}{c}\text { Awareness of presence } \\
\text { of data }\end{array}$ & Yes & May be & Yes & May be & NA & NA \\
\hline Control & Yes & NA & Yes & Yes & Yes & NA \\
\hline
\end{tabular}

Table 5.2: Factors driving attributes of transparency

From the relationship matrix, it could be seen that technology availability and technology usability has a more significant impact on most of the characteristics. The two drivers could be compounded as a single driver Technology. The availability of specific technology increase usage rate, but the usability is dependent on other aspects which will be discussed further in Chapter 6. The location of data and availability of the data could be combined as the visibility of the data, as visibility implies the presence of data at a location that can be seen by themost.

\section{Keys are Impacting the Drive Towards Transparency:}

The other aspect of the interview was measuring the current level of transparency in the purchasing organization and what the respondent desire it to be in the future. The data for the perceived transparency level now and future expected level are measured both for internal and external parts of the organization. The summarized response of all the respondents is as shown in fig 5.3. Most of them agree that the current transparency level is $50 \%$ external and $65 \%$ internally. However, the difference with the desired level is 30\% externally and $25 \%$ internally. 


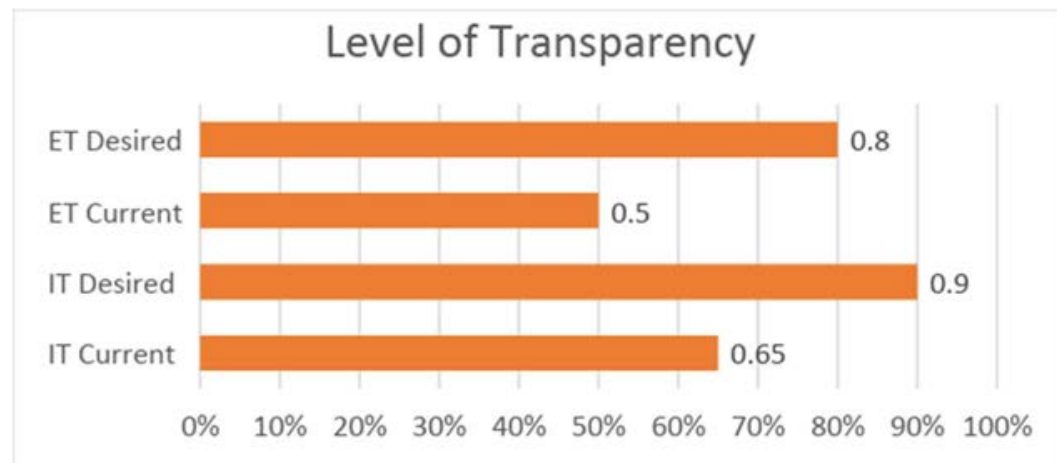

Fig 5.3: Respondents opinion on current and desired transparency levels

The further set of question focused on understanding the primary reasons for the existence of the difference between the current and desired levels. When probed into the questions and based on the most recurrent responses, a fishbone diagram has been developed to understand why there is a lack of transparency to the desired level as shown in Fig 5.4. Based on the various aspects discussed in the interviews, four favorite themes have evolved related four main elements of a transparent system namely locating the data, accessing the data, securing (getting) the data and finally using the data.

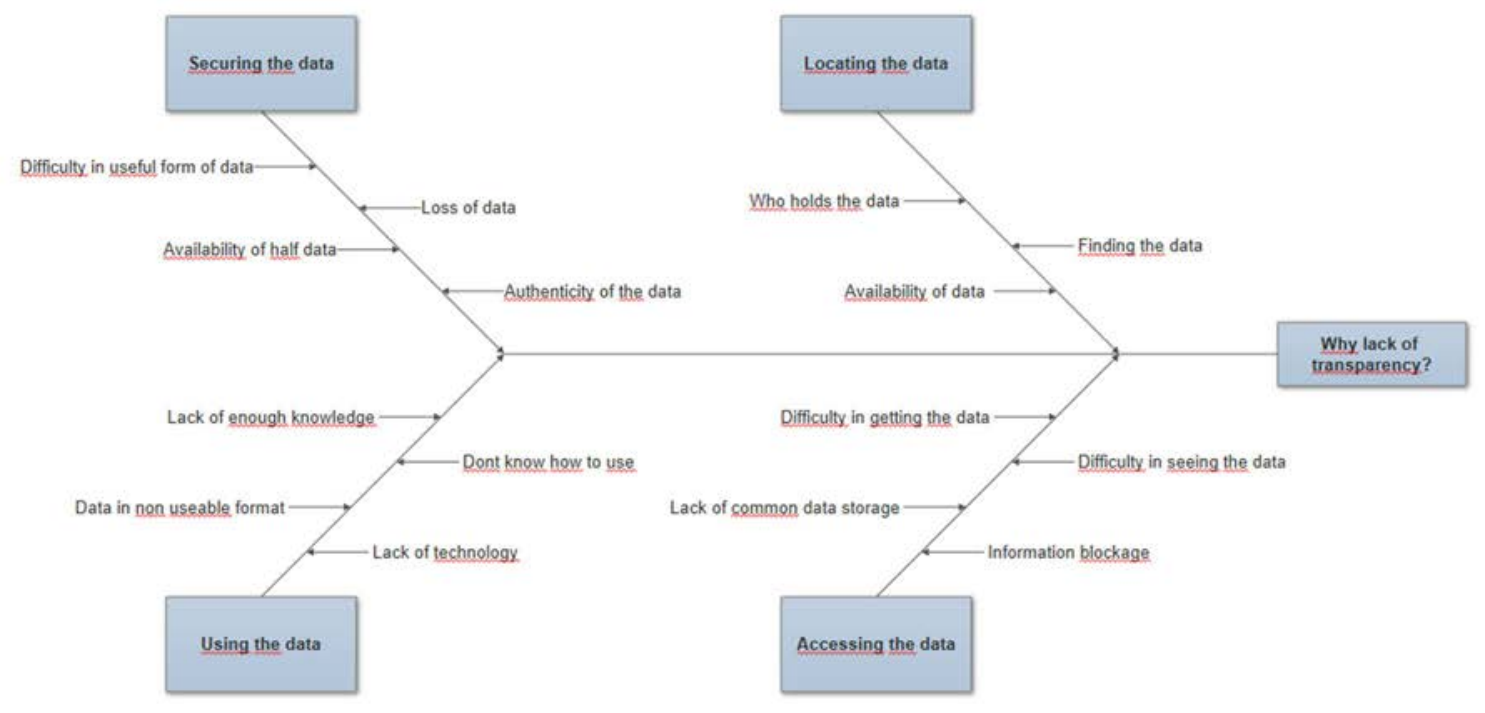

Fig 5.4: Cause and effect representation for lack of transparency

However, this is peripheral problems with several reasons impacting them in different forms. There are several themes which have evolved over the probe using fishbone reasons and action research with SKF employees. Some ideas are recurring and mutual effecting, whereas few are having a combined effect on the four fundamental problems. The more in-depth study has resulted in 7 key areas which had impacted the four external factors and ultimately affecting the level of transparency. The seven key areas and their problems being influenced by them are presented by the relation chart shown in fig 5.5. The key areas are internal alignment, unclear roles \& responsibilities, knowledge management, technology adoption, competence, standardization, and utilization. Technology adoption has a significant impact on all the four problems as is seen by most as the importance that needs to be addressed to the benefits of both 
the present and the future.

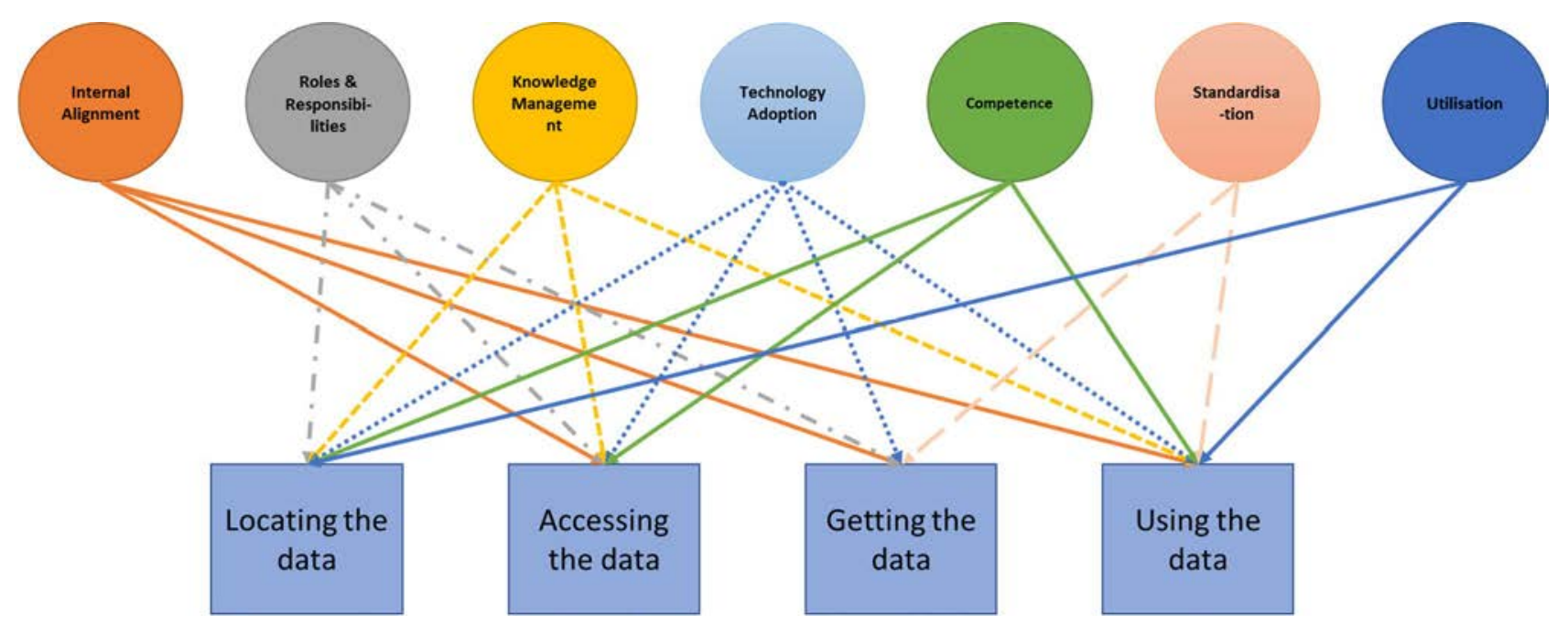

Fig 5.5: Interaction between key areas impacts factors responsible for lack of transparency 


\section{Chapter 6: Discussion}

This section details into the analysis of empirical findings from interviews at SKF and would be studied in combination with the theory to frame solution to the research questions.

\subsection{What is Transparency?}

The general concise from the various theoretical work conducted on the subject topic, transparency in a functional department of an organization, could be defined as "The extent to which information about the activities, suppliers, information and sourcing locations is readily available to end-users and other stakeholders in the supply chain.”

Most of the SKF employees see transparency as something which is related to sharing of the information. The most common denomination used for the same is data, as all the information, both formal and informal, forms the data set for daily decision making at SKF. This observation aligns with the theoretical meaning of transparency which also emphasizes the availability of the information to all the stakeholders within the organization's function. This sets the context of the discussion in the single frame, where data is the key aspect of defining transparency.

The second most common theme emerged from the interviews is means through which data is shared, implying the communication or transfer means of the data. As (Ref 6.1) stated the important aspect of the transparent function is the path through which the information is shared. That emphasizes the chocking points in the way which defines what level of transparency is present in the researched function or organization. The alignment of theory and common themes regarding means of communication iterates the reasoning that the importance of communication in defining the term transparency. In a transparent environment, the value of the data in taking action or decision is the most important one.

The availability of the information cannot represent the true meaning of transparency if the intended purpose of the data is not fulfilled. Thus, in a defining the term transparency in a purchasing organizational context, it is important also to define the ability to comprehend and use the data. The same has been the popular opinion from most of the interviews conducted at SKF and outside. Taking the subjective nature of the term into consideration and other recurring themes from the interviews, a holistic meaning of the term transparency in purchasing organization need to include the terms data, communication means and usability aspect of the data.

\subsection{Drivers and Factors Impacting Transparency}

The understanding of the attributes and drivers of the transparency is predominantly essential to managing the push towards establishing a transparent supply chain. The subjective nature of the term transparency makes this need even more important. This subchapter discusses the various factors which enhance transparency and explore a recurring theme from the interviews to identify the critical attributes of Transparency in Supply Chain Upstream (Purchasing).

\subsubsection{Attributes}

From the 30 interviews conducted at SKF and external stakeholders, different keywords from the subjective indicators of transparency are identified as detailed in chapter 5.3. From the below figure it could be seen that nine main indicators have been used popularly for defining a 
transparent purchasing organization. The recurrence of these keywords across all the interviews are numbered as shown in the chart. Openness and traceability have been considered popular with 26 mentions, whereas the factor control is mentioned as the least number of times with five mentions.

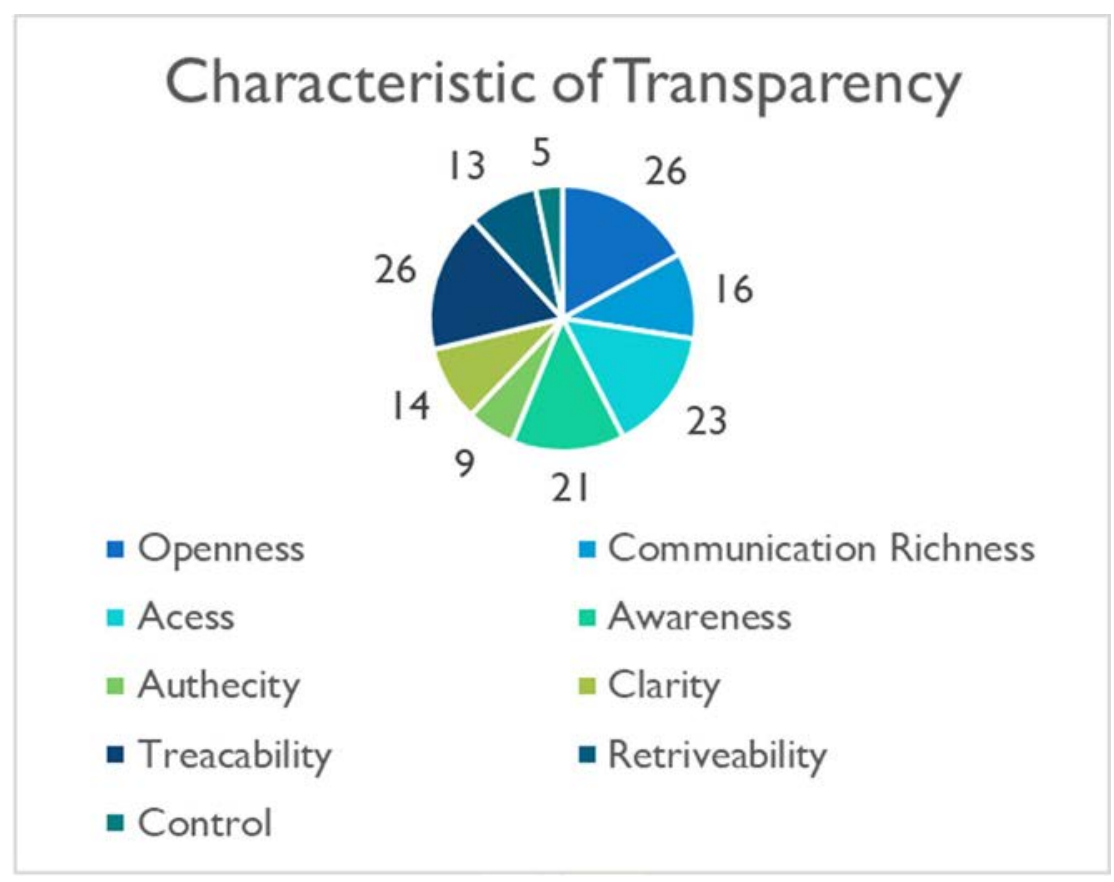

Fig 6.1: Attributes of transparency

The consensus has been observed on four main factors which most of the interviews believe is core aspects of a transparent purchasing organization. Thus, the elements Openness, Access, Traceability, and Awareness are established as the key drivers. This aligns with the general observation from the literature study. As the definition of the transparency itself stresses the need for availability of information to all stakeholders in the supply chain, the validity of these factors as critical attributes of term transparency could be established.

As (Sun, Wang \& Zhang, 2017) says, the central aspect of a transparent organization is traceability, accountability, communication, and governance. The factors traceability being a commonality from the research study and literature, it could be considered as the key attribute of a transparent supply chain. The backend understanding for the prominence of this term relates the ability provided by the information sharer to check and retrace the path from the origin of specific data till it the current state. This factor gains more importance in purchasing organization because of the need to keep track of the information related to any task (maybe purchasing or negotiation) to align with legal compliance requirements and ethical practices laid by the governing organization - the ability to trace the origin of information till its further processing is predominantly high in sensitive areas like defense and aerospace, where stringent rules are applicable for every business transaction including sharing of information. Adversity of these factors could lead to complication in the organization business and could cause harm to the reputation of the organization \& its employees. Thus, it could be summarized that traceability is the critical attributes of a TSC.

The other three factors even though don't directly align with the literature, the internal correlations between the elements provide a base on which the elements can be considered as 
attributes to transparency. As the meaning of transparency high the need of availability of the information to the stakeholders, the factors access which itself controls the availability aspects also forms the critical attribute to TSC. An unhindered or at least controlled access to data enhance the reach of the data to the requested user, which constitutes the core form of a transparent system. The access factors jointly governed by the literature established factor communication. The communication and channels of sharing define the level of access and thus are indirectly connected. The entrance to data would be futile unless the user understands the presence of the data and its intended purpose. The availability of data which user has minimal understanding of how to use or where is used, adds minimum value to the organization functioning. Particularly these factors in conjunction play a vital role in purchasing organization day to day functioning. An open data with a minimal understanding of where to use could be harmful to purchasing organization, where the data is critical negotiation factor governing purchasing effectiveness. As the CPO mentioned, overtly sharing of data to someone who doesn't know how to you use could be impact purchasing functions overall competence.

As (Davenport and Low, 2013) states, accountability, and communication are critical attributes of a transparent organization functioning, the accountability factor defines the need of the user and data sharer to own the validity of the data to the intended application. It provides authenticity to the data or information shared, which is also crucial aspect controlling significant business transaction of purchasing function and their direct relation to the supplier. The same has been indicated by many interviews with mentions of terms of authenticity and clarity. The other aspect which didn't find many remarks in the discussions is the ownership of the information. The ownership of information is critical to maintain its authenticity and traceability aspect which are highlighted both in the interviews and literature. Thus, the factors authenticity, control, and ownership could be considered as other attributes which need to be regulated in the drive towards a TSC.

The other aspect which found equal importance both in literature and interviews is the communication factors. An active communication channels are essential to ensure the leakage of information is avoided, and originality could be retained. The same is true in general understanding that information or data in verbal form could be transformed during the process of transferring from one source to other. This modification in data context or loss of information could lead to substantial business damages. As highlighted by one of the interviewees of change of data from one user to other has affected a business relationship with a Chinese supplier. The gross misinterpretation between the transfer points has led to colossal miscommunication which leads to SKF wrongly charging the supplier for almost 250000 SEK for replacements. On retaliation from the supplier and internal probe has led to the root cause, where information misinterpretation at the transfer points lead to the communication of wrong inputs to the supplier, causing both monetary and business damage to SKF with respect to its strategic supplier. Thus, it could be concluded that factors highlighted from the interview apart from retrievability are the critical attributes of TSC. An additional element of ownership is also added to list in consideration with the factors value addition to purchasing functions effectiveness.

\section{Drivers of Transparency}

From the discussion on the different attributes of transparency, it is also important to understand what drive these attributes and ultimately leading to a step towards a more transparent business functioning. From the interviews, many drivers which boost these attributes were identified, but with the recurring theme and common logic among the various driving factors, the following three broad segments are classified as primary drivers of the attributes of 
transparency. They are visibility, communication, and Technology.

\section{Visibility:}

The key attributes to transparent function are access, authenticity, control, and ownership. These attributes high light the importance of the presence of data, its originality or richness, quality of data and accessibility of the data to the desired user. However, all these factors can only gain importance when the desired understand the actual presence of the data which he desires, where it is available and how it can be used. These three aspects are directly related to the ability of the user to see and visualize the existence and availability of the data. The full explanation of it is user awareness of the presence of information, what kind of information, the form in which it is available and what could be made out of the data. This form the crux of driver visibility. The importance of these drivers was highlighted by the examples quoted by the senior management. As CPO says, the only form of effective working is by understanding what is available and effectively using it to minimize the losses and maximize value addition. An example quoted for this was the performance of one category segment before and after the initiation of the business analyst team. Before the business analyst team was established, only a few knew about the available information which could be used to minimize spending and optimize procurement process. The evolution of business analyst team has added other competence to the strategic sourcing initiative of SKF and has resulted in better risk management, effective decision making, better supplier management and over additional spend saving to the tune of 0.5 billion SEK. Thus, the visibility of the data improves real awareness among the stakeholders and simplifies the sharing of information. The profile reduces the time which is needed to identify the location and retrieve it.

\section{Communication:}

This driver effective runs the way in which the information or data is shared. A transparent function is where the communication path is open, comfortable and leak proof. The effective communication system enables the ability of the user to secure the information in its authentic form without any alterations enhancing the usability aspect of the data. The communication drives the sharing of critical data across the stakeholders and increases the trust factor which the central element in a transparent organization. As one of interviewee stated an active channel or medium of communication brings down the barriers among individuals. It enhances the trust and leads to mutual sharing of knowledge, thus not only supporting transparency drive but also improving internal competencies or developing shared skills.

\section{Technology:}

With the availability of the technology the drive towards a transparent system has gained more impetus. Availability of technology and optimal utilization increase visibility and creates an effective communication system. Technology is a prominent driver who drives all the attributes of transparency both individually as well in combination. Usage of technology enhances traceability as evident from SKF Star Ariba platform, where all the contracts and RFQ's are stored in a central system with access to all the stakeholders. The immediate impact of this system was effective contract management and helped in reshaping the global purchasing aspects of SKF. Implementing new technologies and adapting it to regular work has an impact on the accessibility, control, authenticity and assumes ownership of the data. With higher impact on them, all the essential attributes Technology can safely summarize a critical or prominent driver of Transparent Supply Chain. 


\subsection{What are Key Needs for a Transparent Supply Chain?}

This subchapter discusses the key aspects which need to be considered and implemented in a drive towards making a transparent purchasing organization. The subchapter addresses the analysis of the findings from the interviews and uses the inputs acquired through action research conducted along with an SKF group purchasing employee. The results even though specific to the case studies in the study, these issues or needs apply to all the purchasing organizations mainly for global manufactures (Tier 1 majors).

\section{Key Points to be Addressed in Drive to Transparent Function}

Based on the need to establish transparency and on understanding the subject perspective of its attributes and drivers, some key issues are identified which could derail the process. The problems are evaluated by conducting root cause analysis of the variation between the desired and expected state of transparency. The causes which are relevant in the present organizations functioning, if focused could help in a push towards a more transparent function. There have been seven main segments which are identified to cause functional instability and lack of trust directly impacting the transparency levels within the organization. The seven key areas or issues are as detailed in the below picture. A detailed discussion on why the areas are essential and how they are impacting various attributes/drivers is discussed below.

\section{a) Roles and Responsibilities}

In the current form the organization particularly matrix organization with a focus on category strategy, this area or aspect plays a major role. As (Vantrappen \& Wirtz, 2016) says, in a matrix organization where coordination is the key element, clearly defined roles, and responsibilities is predominant to ensure the effective functioning of the organization. Clear roles and responsibilities, provides an individual or employee to understand the boundaries of his work role and the activities or information or tasks for which he/she is responsible for what. Clear defined roles and responsibilities ensure every information or task is accountable by the respective individual for which he owns the ownership. A clear defined role means an external user seeking information or a certain set of data knows who owns the data and who need to be approached. Holding accountable for some task or information ensures the authenticity and traceability aspects of are maintained. This helps in not only saving the time but ensure the richness of data is maintained during the transfer.

It could be observed that clearly defined roles help an organization to ensure traceability, authenticity, accountability, information richness is maintained. This is elements the key attributes of the transparency. Thus, clearly defined roles and responsibilities could help in establishing the drive to transparency on the right path. In real time, as evident from the interviewee's response, a lack of understanding on the roles and responsibilities leads to duplication of information, long and tedious wait for finding the information, lack of authenticity and loss of data through transfers through multiple points. An example cited by one the interviewee is that a lack of understanding among certain category managers led to the ill implementation of few strategies. In an incident, the lack of knowledge of how holds a certain set of contracts with a supplier led to long searching activity. The lack of clear view into who is responsible for the contract made it difficult to trace it back, which if they couldn't find could lead stoppage of supply to the Gothenburg factory.

Thus, before initiating a drive to transparency, it is equally important to define the roles and 
responsibilities clearly. This will help in enhancing the visibility across the function, leading better results ultimately improving the trust among the actors of the function.

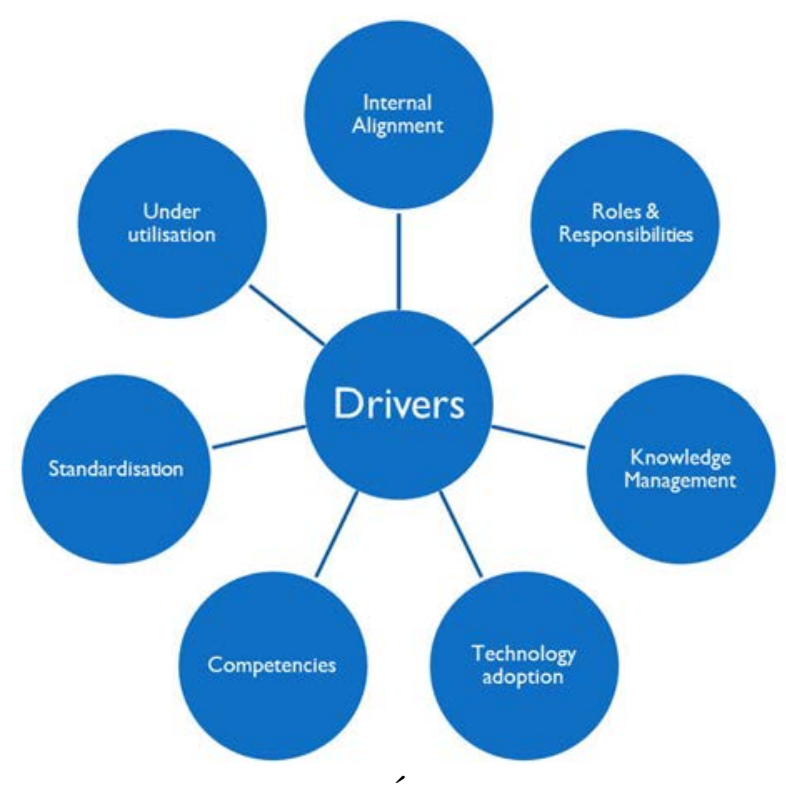

Fig 6.2: Key areas of focus in drive to transparency

\section{b) Knowledge Management}

Knowledge management is another critical area which needs to focus upon in a drive towards transparency. Knowledge, an intrinsic form of data or information, is essential to enhance the ability of the individuals to understand and use a specific set of data which he is naive too. Handling effective knowledge management also ensures to remove internal barriers among the stakeholders which improves communication while sharing some information or data. From the responses of the interviewees, a clear pattern of information blockage could be noticed among the category purchasing and factory purchasing. This led to the ill implementation of strategies without understanding the complete nuances of the process. From the action research, one key issue was highlighted concerning knowledge management. There is an inherent restraint from both the category and factory purchasing with related to the opposite side understanding of other's problems. One incident briefed, was the factory purchasing believe the category management doesn't know the factory or local needs creating a belief that a single strategy is being developed. On the other hand, the category team believes that the factory side didn't understand the benefits of global scenarios and developed an internal belief that they are reluctant to change. This created a lack of trust and dominant relation is to establish where the communication channel is deliberately clogged. This has affected the transparent functioning of internal purchasing organization and had impacted the supplier management with both sides indulging in flavorist treatment.

On the contrary, a recent change of position of factory and category manager roles has wholly changed the functional scenarios of the region. The job rotation has helped both the individuals to understand the constraints and soft factors of each side which assisted in developing a more collaborative relationship between the category purchasing and factory purchasing team - the result of this better collaboration and higher transparency at a regional level. This change not only improved the partnership but also showed impact in strategy implementation and business performance. Thus, effective knowledge management could impact the trust and 
communication between the stakeholder, improving the transparency levels within the organization.

\section{c) Technology Adoption}

As Davis (1985) quoted a technology which is not in use is equal to non-availability of the technology and waste. It is predominantly essential to use the technology or increase the using rate to leverage potential provided by the technology. As evident from the research, Technology is one major factor which enables and trusts the drive towards achieving transparency. The ability to provide any data at any given time is the true meaning of transparency which states availability of information to all the stakeholders within the organization. However, the potential of technology to boost the transparency levels can be seen only if the technology is brought into use. Unfortunately, that is the significant aspects which form the most considerable blockage in an organized move towards a transparent functioning. This is being clear in case of our case study SKF. They have taken a few steps in incorporating technology into working, which unfortunately failed to deliver the anticipated results. The failure here doesn't mean the collapse of the technology. When studied about why it SKF couldn't realize the full potential of the STAR Ariba, we have realized a non-harmonious pattern among various plant locations in Europe. Few of the areas like Gothenburg have achieved results within quick time, whereas the some other failed severely. When detailed researched, it was found that the user adoption of the technology in the Gothenburg area was better and the user's using rate is comparatively higher than the other locations across Europe. Several reasons are contributing to the same but are specifically highlighted, one change management and another adoption process.

Technology adoption is a psychological process, where the user needs to understand the intention to use the technology. The technological adoption could be boosted, when the user understanding of the technologies perceived benefits is positive. It could be either reducing his effort or adds value to the activity performed. This perception is affected by how the change management is carried out. The change process needs to be carried into consideration with human aspect involved and continually evolving needs of the user. Technological adopted if focused better could help in increasing the functions abilities along with boosting up transparency within the organization. A bad adoption process could lead to adverse effects on the function ability to change the demands of the market or fast developing technologies like eprocurement, AI or blockchain.

\section{d) Competencies}

The central aspect of transparency is the user ability to secure the data and their ability to comprehend and use the data. Here is where the competencies of the user are key. The skills of the user and the source are of crucial importance to the usability aspect of the data. The competencies of the user are essential for adoption and using of technology. The, in general, are related to the direct performance of the user in the designated role. Mismatching of competencies to the role requirement could lead to fitting the wrong resource at a wrong place. Thus, ensuring the right skills are gained and matched to profile requirement indirectly affects the effective sharing of information, as is the drive towards a transparent environment. 


\section{e) Underutilization}

Alike competencies, the underutilization of the individual capabilities also leads to affecting the technology adoption process and the intrinsic motivation in the drive towards transparency. Underutilization diminishes the morale of the individual from doing innovation at the work role level, leading loss of opportunities to improve the process. On the other hand, the resources are utilized to the best possible manner, increases the employees trust in the organizational culture and provide better chances of co-innovation, which boost both internal and external capabilities of the organization.

\section{f) Standardization}

Being a global organization SKF is, the possibility of data existing in various form is comparatively common. However, with the change in consumer needs, the stake for worldwide alignment and amortization of business practices have come into force. The extensive application capability of the data is the predominant driver of this global alignment process. However, the existing of consistency in the data across all the units could impact the alignment and usage value of the data. Incompatible data from multiple locations hinders the process of global alignment which is the key for driving towards a TSC. The TSC is characterized by the value of the data and quality it carries which could be impacted by the nonstandard process lying across the organization. The second pressing need for standardization is to establish a global operation and minimize the efforts for communication same information or practices across the organization. Lack of uniformity impacts the change process which has the effect both financially as well as drive towards an effective information transfer, usage. On the other hand, standardization of practices ensures the information generated has more quality, aligned and validity to be of use for decision making impact the massive organizational change. Standardization ensures the traceability and accountability aspects are enhanced in an organization boasting its drive towards transparency.

\section{g) Internal Alignment}

The most significant and essential factor having a comparatively higher impact on improving transparency is the lack of internal alignment. Internal alignment is of higher importance when the organizational footprint is broad and spread across the world. Lack of internal alignment could create potential barriers having an impact of sharing of information with the organization as well as the consistency of information passed on to external stakeholders. Lack of internal alignment also affects the trust factor among employees which could have both personal and professional barriers creating disharmony. Trust is essential for the transfer of information in a rich context, and lack of trust could have a direct impact on this. Thus, the traceability, usability, accountability of data is disarmed with effects on the transparency internally. With lack of internal alignment, the possibility to have a familiar face to the external stakeholder would be impacted affecting the market confidence in organization or function as such. 


\section{Chapter 7: Conclusion}

The chapter summarizes the findings of the thesis research conducted on the supply chain transparency. The section answers the three-research question and explains how the study could be used for exploring or initiating a drive to be more transparent but within personal boundaries of a purchasing institution.

\subsection{What is Transparency?}

Transparency, as established by the literature, is a more of a subjective term that an objective term which is universally applicable. Even though the general meaning of the term transparency of being open and provide visibility to all involved stakeholders hold ground, a more subjective definition helps the organizations in focusing and aligning their drive to be more transparent.

In a purchasing organization, where most of the decisions based on hard facts and data, the need to be transparent is critical. However, at the same time, complete transparency evades the negotiation power of the department, which could have potential business impact. As the CPO mentioned, the organization need to $100 \%$ transparent within the organization but need to be careful to handle the factor when dealing with external stakeholders like suppliers or sister companies. This would ensure that negotiation strategy could be safely deployed to achieve a better margin, which is of high prominence in the current competitive market. Based on the responses from the interviews, a more customized definition of transparency is hypothesized as

\section{"An open environment where the end user could see, retrieve and use data as requested by him. The information access is simple, and data is easy to use"}

This definition is valid to the purchasing function across the organization, as it is developed from interviews of respondents working in purchasing domain and considering their general work role. However, with similarities in the base logic of buying holding the same across all organization, the definition could be safely adopted all industries across the segments for their purchasing functions.

\subsection{What are Key Attributes and Drivers of a Transparency?}

As the definition of transparency includes key terms like open, visibility, usability and access, the attributes of the transparency need to be supporting or related to these keywords. Based on the respondent's responses evaluation combined with a literature study, eight critical characteristics of transparency are defined as detailed below.

a) Traceability: The ability to trace the generated data right through the line of evolution from the source of origin to the current form. This attribute form key in understanding how the information has evolved and provided more clarity into its originality

b) Access: The ability of a user to get the information he desired. This attribute establishes the ability of individual stakeholders in the organization to retrieve the data he intended to have.

c) Awareness: This attribute aligns with the usability aspect of transparency definition. The awareness indicates the user ability to understand the availability of the data, its location and how to use the data 
d) Openness: The aligns to simple access, where there is an unhindered but regulated (sometimes) access to data or information, the stakeholder desires

e) Communication: This attribute refers the ability to secure the information in the form it is present. The communication means ensure data leakage or duplication during the transfer process having a direct effect on the trust factor

f) Control: This attribute aligns to the validity of the data or process. The control could be on avoiding the manipulation of data or misuse of the data in the process of sharing, as data form the competitive factor in the negotiation process

g) Authenticity: This attribute governs the originality of the data or righteousness of the data.

h) Ownership: This relates to the accountability of the righteousness of the data. The ownership of the data ensures, its original form is safely stored to be used for the intended purpose.

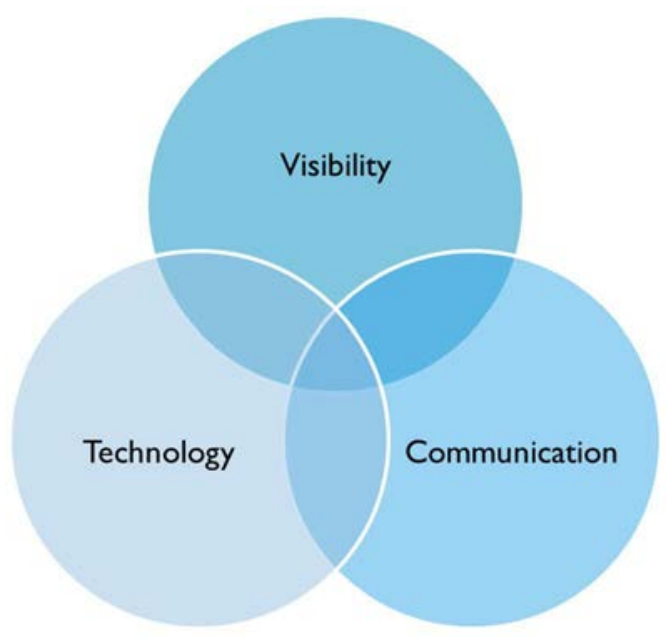

Fig 7.1: Visual presentation of drivers

Over-careful analysis of the different attributes and what drives the attributes, three unique aspects have been identified. The three factors are visibility, communication, and technology. While the first two drivers are more internally developed aspects boosting the transparency drive, technology is one external aspect which could be integrated to the organizational practices. Technology helps in promoting the first two drivers. A study of future technology in the purchasing function generates a bright prospect for enhancing the internal transparency of a purchasing organization.

\subsection{Keys Areas Influencing Level of Transparency}

The biggest reason for the failure of the movement to a more transparent functioning's is the lack of awareness of factors impacting the transparency levels in the organization. The four problems identified in the research are the one which is referred in the explanation of word transparency. The location and access of the data are directly related to the critical aspect of the availability of the data to the user, securing the data is directly related to the ability of the user to get the desired available data. The last of transparency is the ability of the user to make use of open data they retrieved and is impacted the ability to use the data or usability of the data as such. The generalness of these four problems, make them less visible until unless the user faces 
the actual challenge.

The actual movement to transparent supply chain or seamless purchasing could be achieved when these four problems are regularly monitored and reviewed. The ability to address these problems is acquired only when the key areas are effectively managed. The seven critical areas highlighted are a pretty much common issue that are visible but often ignored. For example, significant organizations have standardization as practice across the division and functions. However, maintaining the standardization is a problem. Here along with standardizing the data or process, it is also equally important to monitor the standardization practice. Similar logic goes with roles and responsibilities which most assume to present but do everyone has a clear understanding of them is always a question which pops up in the pressure situation. A bitterly designed and monitored roles and responsibility remove the confusion and provides the path for the clear understanding of who does what and who possess what kind of information. Technology management is the critical area which every organization and function need to address. The availability of the technology would not fetch any benefit to the organization until unless it is used by the members of the organization. The usability aspect of technology would be only improved when the technology adoption process is made robust and tailored to the needs of the organization members. A better-planned technology adoption process and success could increase the competencies of the organization to handle future technological changes effectively. The better skills could be leveraged to add value to the whole organization. As against, an ill-handled technology adoption model could hinder the future organization capabilities to adjust to changes in technology and flexibilities demanded by the market. A step towards addressing the key areas affecting move towards transparency will not only improve transparency but also would increase the organization capabilities for the future uncertainties. 


\section{Chapter 8: Recommendations}

The research into understanding transparency in a supply chain focused on purchasing function of an organization has provided focus on various needs for moving towards a transparent environment. Based on the findings, their impact on the organization along with literature, few recommendations have been made. Though the recommendation is focused on SKF, they are still valid for all the purchasing organization. The recommendations have been made of three key aspects of change management, technology adoption, and competencies.

\section{Change Management}

Though the subject looks big with extensive studies done on big changes like organization restructuring, change in the way of work doesn't mean change management and its theories are applied only on large-scale transformations. Change management principle need in applied at small level changes including software's used for regular work - the transition whether big or large need to have change driven effectively. In consideration to the few recent transitions happened at SKF, the following two recommendations are made.

\section{a) Develop Local Change Drivers:}

In a multinational like SKF with factories and offices located across the world, handling the change from a specific location (mostly headquarters) is technically a big challenge. Even though the central team has competencies to drive the change, the logistical and time constraint possesses them challenges to be omnipresent. Having a leader to drive the change is an essential ingredient for the successful change. Thus, the need for local change driver gains more prominence. However, as the change is a non-recurring activity, specific change leaders completely focused on driving the change is not needed. Thus, a local team member needs to be nurtured from early stages to take the role of local change driver based on need.

\section{b) Integrating Process Learnings:}

Generally, most of the processes learnings are recorded only after the completion of the change drive. However, in a multinational organization with factories located across the world, a wave process of implementation is adopted. This wave process is like stage gate models, thus providing a regular gate, where learnings need to be accessed, and the change process needs to be adapted to integrate the learnings. This aspect avoids recurrence of problems and an everevolving change process suitable to the organization personal involved.

\section{Technology Adoption}

With recent development in new purchasing tools and technologies, there is an imminent need to acquire and adopt new technologies. The complexity of the new technologies is very more extensive than the one available now. Adopting technologies like AI, E-procurement, blockchain need the organization to be stabilized and agile in its current form. Based on the study on technology adoption model and recent technology adoption at SKF, four main areas are identified first for stabilization of the existing ground and developing agile qualities for the future as shown in figure 8.1. 


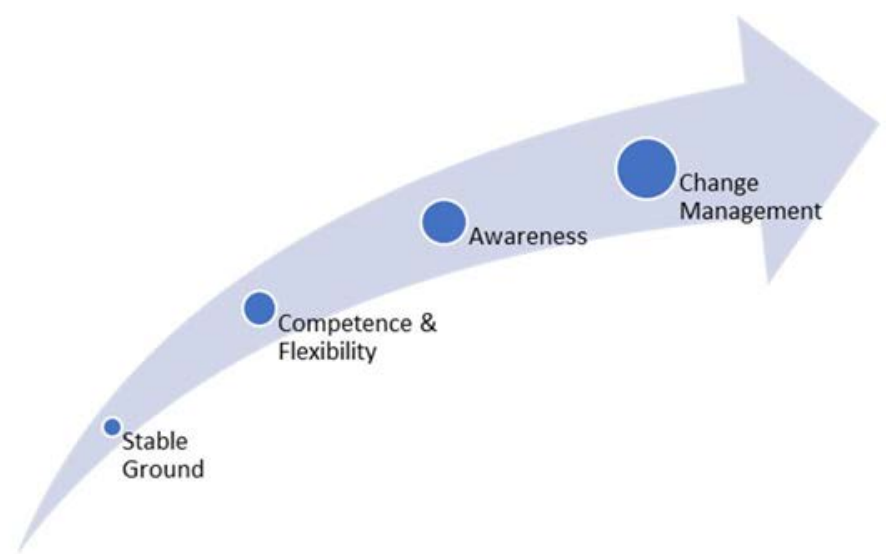

Fig 8.1: Path to increase flexibility for future adoption

There are several recommendations for gaining the stability and developing flexibility, but two initial proposals which are predominant for purchasing functions of all organization are detailed.

\section{a) Technology Adoption-Flex Training:}

For a large organization like SKF, a single training scheduled is conducted at every location with the infeed of all possible information about the new technology. It is the most common practice across the many major organization, for example, Volvo cars had a 3-day training program on an agile way of working. This most reasonable explanation provides for arranging this training approach was the substantial cost involved in providing multiple training sessions. The critical question here is, are this single training session making the expected impact. The most popular answer received during our research is a firm NO. The underlying reason is the particular psychological restriction in absorbing all the information provided in training and using the next day in day to day life. The recommendation we provide is developing a training program which is a combination of classroom training, online seminars, and web learning. The approach allows only absorbable information in the classroom training by expert and stimulates learning through intrinsic motivation to explore. The webinars and web learnings could answer the answer to this question raised to own curiosity. This method effectively handles the conflict of adoption and financial burden.

\section{b) Developing Competencies:}

As the TAP model states, a technology could only be adopted when the user perceived the benefit of the technology. However, recognizing the benefit depends on the user's ability to visualize the benefits, which would only come through awareness. Developing awareness and raising the competencies will improve the flexibility of the organization to adopt new technologies evolving in the market. The user awareness and competence can be enhanced through training, but an alternate and financially feasible approach is also available. That's is through collaboration and co-innovation. Collaboration and co-innovation are the most significant drivers of developing competencies which are naïve to most of the world. There are many forums which conduct open discussion and co-innovation platform providing an alternative to the expensive training programs. 


\section{References}

Ajzen, I. and Fishbein, M. (2002). Understanding Attitudes and Predicting Social Behavior. Upper Saddle River, N.J: Prentice-Hall.

Albu, O. and Flyverbom, M. (2016). Organizational Transparency: Conceptualizations, Conditions and Consequences. Business \& Society. doi: 10.1177/0007650316659851

Anon, (2018). [online] Available at: http://blog.castuk.com/2016/09/05/10-reasons-whysupply-chain-transparency-so-important [Accessed 11th May 2018].

Bain, M. (2018). Global Companies Get Too Much Credit for Their Transparency. [online] Available at: https://qz.com/938161/global-companies-get-too-much-credit-for-theirtransparency/ [Accessed 28 Apr. 2018].

Bingi, P., Sharma, M. and Godla, J. (1999). Critical Issues Affecting an ERP Implementation. Information System Management, 16(3), pp. 7-14.

Bridges, W. (1986). Managing Organizational Transitions. Organizational Dynamics, 15(1), pp. 24-33.

Burke, W. (2002). Foundations for Organizational Science. Organization Change: Theory and Practice. Thousand Oaks, CA, US: Sage Publications, Inc.

Cameron, E and Green, M. (2004). Making Sense of Change Management: A Complete Guide to the Model, Tools and Techniques of Organizational Change. Kogan Page Limited, Great Britian.

Cao, M. and Zhang, Q. (2010). Supply Chain Collaboration: Impact on Collaborative Advantage and Firm Performance. Journal of Operation Management, 29(3), pp. 163-180.

Cao, M. and Zhang, Q. (2013). Supply Chain Collaboration. 1st ed. London: Springer.

Davenport, E. and Low, W. (2013). From Trust to Compliance: Accountability in the Fair-trade Movement. Social Enterprise Journal, 9(1), pp. 88-101.

Davies, I. and Gutsche, S. (2016). Consumer Motivations for Mainstream "Ethical" Consumption. European Journal of Marketing, 50(7/8), pp. 1326-1347.

Davis, F. (1985). A Technology Acceptance Model for Empirically Testing New End-User Information Systems. Doctoral dissertation, Sloan School of Management, Massachusetts Institute of Technology.

Davis, F., Bagozzi, R. and Warshaw, P. (1989). User Acceptance of Computer Technology: A Comparison of Two Theoretical Models. Management Science, 35(8), pp. 982-1003. 
Deloitte Insights. (2018). The Path to Supply Chain Transparency. [online] Available at: https://www2.deloitte.com/insights/us/en/topics/operations/supply-chain-transparency.html [Accessed 1 May 2018].

Diaz-Chao, A., Miralbell-Izard, O. and Torrent-Sellens, J. (2016). Information and Communication Technologies, Innovation and Firm Productivity in Small and Medium-Sized Travel Agencies. Journal of Travel Research, 55(7), pp. 862-873.

Egels-Zandén, N. and Hansson, N. (2015); Supply Chain Transparency as a Consumer or Corporate Tool: The Case of Nudie Jeans Co. Journal of Consumer Policy,39(4), pp. 377-395.

Eljazzar, M., Amr, M., Kassem, S. and Ezzat, M. (2018). Merging Supply Chain and Blockchain Technologies. In: The International Maritime Transport \& Logistics Conference (Marlog 7). The Gateway to the Future, pp. 1-7.

Gattorna, J. (2003). Gower Handbook of Supply Chain Management. Aldershot, Hants, England; Burlington, VT, USA: Gower

Gereffi, G., Humphrey, J. \& Sturgeon, T. (2005). The Governance of Global Value Chains. Review of International Political Economy, 12(1), pp. 78-104.

Ghobakhloo, M., Hong, T., Sabouri, M. and Zulkifli, N. (2012). Strategies for Successful Information Technology Adoption in Small and Medium-sized Enterprises. Information, 3(1), pp. 36-67.

Globalscan, (2017), Values, Innovation and Transparency Key to Future Corporate Sustainability Leadership: Latest Survey of Experts [Online], Available at: https://globescan.com/values-innovation-and-transparency-key-to-future-corporatesustainability-leadership-latest-survey-of-experts/ Accessed: $11^{\text {th }}$ September 2018

Güler, S. (2010). Change Management A Case Study of SAP Implementation in a Major Company. Gothenburg: Chalmers University of Technology (Degree Project - Department of Civil and Environmental Engineering, Chalmers University of Technology, no: 2010: 132)

Hiatt, J. and Creasey, T. (2003). Change Management: The People Side of Change. Prosci Research, Lovelard, Colorado, USA.

Hofman, E., Beck, P. \& Fuger, E. (2013). The Supply Chain Differentiation Guide. Berlin, Heidelberg: Springer.

Larry, A., (2017), How Transparency Became a Top Priority for Businesses, and Why You Should Care, Available at: https://www.entrepreneur.com/article/295739, [Accessed: $14^{\text {th }}$ September 2018]

Nel, D. and Badenhorst-Weiss, J. (2011). Analyzing the Differences Between Theoretical and Implemented Supply Chain Strategies in Selected Organizations. Journal of Transport and Supply Chain Management, 5(1), pp. 299-315. 
Pugh, L. (2007). Change Management in Information Services. Ashgate Publishing Limited, Aldershot.

Sayogo, D., Zhang, J., Luna-Reyes, L., Jarman, H., Tayi, G., Andersen, D., Pardo, T. and Andersen, D. (2015). Challenges and Requirements for Developing Data Architecture Supporting Integration of Sustainable Supply Chains. Information Technology and Management, 16(1), pp. 5-18.

Smythe, E. and Smith, P. (2006). Legitimacy, Transparency, and Information Technology: The World Trade Organization in an Era of Contentious Trade Politics. Global Governance: A review of Multilateralism and International Organizations, 12(1), pp. 31-53.

Sun, S., Wang, X. and Zhang, Y. (2017). Sustainable Traceability in the Food Supply Chain: The Impact of Consumer Willingness to Pay. Sustainability, 9(6), p.999.

Trader-Leigh, K. (2002). Case Study: Identifying Resistance in Managing Change. Journal of Organizational Change Management, 15(2), pp. 138-155.

Vantrappen, H. and Wirtz, F. (2016). Making Matrix Organizations Actually Work, Harvard Business Review Digital Articles. Published: 3-1-2016, p2-5.

Vasarhelyi, M., Chan, D. and Krahel, J. (2012). Consequences of XBRL Standardization on Financial Statement Data. Journal of Information System, 26(1), pp. 155-167.

Young, W., Hwang, K., McDonald, S. and Oates, C. (2009). Sustainable Consumption: Green Consumer Behavior when Purchasing Products, Sustainable Development, 18, pp. 20-31. 


\section{Appendix}

A-1:

Subject: Meeting with Global Category Purchaser

Opening Questions: The questions in this section include your experiences inside and outside SKF. A brief about the work role, responsibilities and the key stakeholders involved in the daily work routine.

1. Could you brief about your professional journey inside and outside SKF?

3. Could you please provide some details into your work role and its responsibilities?

4. Could you tell us about the key stakeholders involved in your daily work role?

About Transparency: The section includes questions concerning some aspects of transparency, to understand your general perspective of the term "Transparency".

1. In your own terms, what is your thought of the term transparency in general perspective and in SKF context?

2. Where do you think transparency could be effective SKF purchasing and supplier handling?

3. Why do you think transparency is necessary in a supply chain?

4. Are there any issues you noticed in terms of transparency in the recent past?

Inside SKF: This section includes questions to understand, the internal transparency and efforts placed to improve it with in SKF. It also includes some questions to gain aspects into cross functional working or collaborating aspects with in SKF.

1. As your work role depends on coordinator with multiple category managers for categories which includes a lot of factories. Could you give some details in how you handle multiple stakeholders? What do you think of these above dependences and how are they managed?

2. As a key link in the web, how do you ensure to manage needs of the factory at the same time keep the central strategies running?

3. How does the decision making happen when multiple stakeholders are involved and how efficient should be the communication from either stakeholder?

4. Where do you get the prerequisites or information you receive for making the decisions in your daily work role?

5. Is it possibly to share about your experiences in effective sharing of the required information among the key stakeholders? Could you brief into some aspects of which could affect the efficiencies of information sharing in this process?

6. How to do you ensure that strategic intent or needs of the final user of the strategy is aligned with your work strategy? 
With Suppliers: This section includes questions about suppliers and doing business with them. The purpose of this section is to understand what could be make for an effective supplier relation and the role of transparency in making them effective and efficient.

1. When initiating a business transaction with supplier, what are the key details you need from the supplier?

2. How do you ensure that details provided by supplier provided details are accurate and appropriate to do initiate the business?

3. In your opinion, what are principal areas in which suppliers need to be open and transparent about?

4. What do you think of benefits or implications of being transparent for an efficient long term or short-term business relation?

5. Could you provide some insight into effectiveness of a transparent supplier relation for co-innovation or using supplier innovations?

6. Could you provide some of experiences in handling several types of suppliers and any instances where lack of transparency has affected SKF business?

7. What could be the possible reasons for any supplier avoid sharing of information to SKF?

8. What could be possible steps which could done to ensure transparency could be enhanced in an organization supplier business?

Closing Questions:

1. What is your final evaluation of current transparency level in SKF and its supplier?

2. What are areas where you think SKF could work on believing effective supplier relation?

3. After the interview what do you think transparency, or do you have an alternate opinion?

4. What do you think are the factors which could enhance and support transparency in the purchasing?

5. What could be immediate actions which could be taken by SKF or suppliers which could impact transparency? 